2. To: (Receiving Organization)

3. From: (Originating Organization)

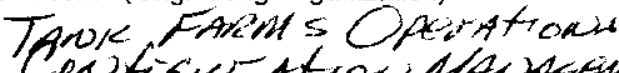

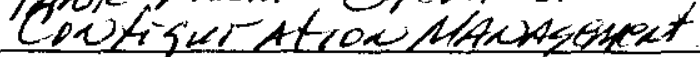

5. Proj./Prog./Dept./Div. $780-182$ (0R979800) 6. Design Authority/Design AgenUCog. Engr.:

C. C. Scaief

8. Originator Remarks:

Attached Document "RPP-5366, Functions, Requirements, and

Specifications for Replacement of the Computer Automated

Surveillance System (CASS)" is attached for review, approval and release.

11. Receiver Remarks:

11A. Design Baseline Document? $O$ Yes $\bigcirc$ No
1. EDT

628217

\begin{tabular}{|l|l|}
\hline \multicolumn{1}{|l}{} \\
\hline 15 \\
\hline $\begin{array}{l}\text { (A) } \\
\text { Item } \\
\text { No. }\end{array}$ & (B) Document/Drawing No. \\
\hline 1 & RPP- 5366 \\
\hline & \\
\hline & \\
\hline & \\
\hline & \\
\hline
\end{tabular}

16.

\begin{tabular}{|c|ll}
\hline Approval Designator (F) & \multicolumn{1}{c}{ Reason for Transmittal $(G)$} \\
\hline E, S, Q, D OR N/A & 1. Approval & 4. Review \\
(See WHC.CM-3-5, & 2. Release & 5. Post-Review \\
Sec. 12.7) & 3. Information & 6. Dist. (Receipt Acknow. Required)
\end{tabular}

DATA TRANSMITTED

SIGNATURE/DISTRIBUTION

(See Approval Designator for required signatures)

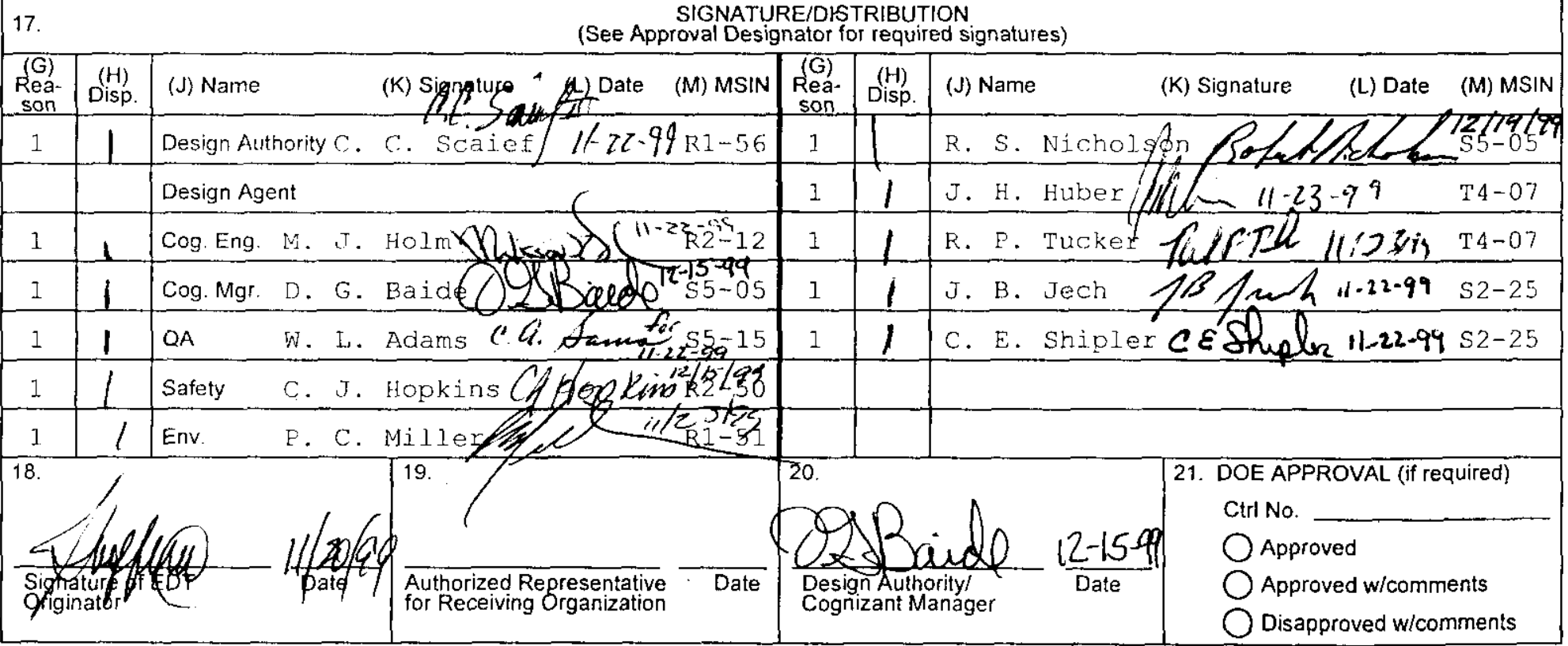




\title{
Functions, Requirements, and Specifications for Replacement of the Computer Automated Surveillance System (CASS)
}

\author{
Lockheed Martin Hanford Company \\ P.O. Box 1500 \\ Richland, WA 99352 \\ U.S. Department of Energy Contract DE-AC06-96RL13200

$\begin{array}{lll}\text { EDT/ECN: } 628217 & \text { UC: } 2000 \\ \text { Org Code: } & 79800 & \text { Charge Code: } 102613 / \text { AJ } 60 \\ \text { B\&R Code: } & \text { EW3130000 } & \text { Total Pages: } 57\end{array}$ \\ Key Words: CASS, alarm, alarms, tank farms, surveillance, functions \\ rupurements, specifications \\ Abstract: Functional requirements and specifications document for system \\ :C replace tank farm computer automated waste tank surveillance system.
}

TRADEMARK DISCLAIMER. Reference herein to any specific commercial product, process, or service by trade name, trademark, manufacturer, or otherwise, does not necessarily constitute or imply its endorsement, recommendation, or favoring by the United States Government or any agency thereof or its contractors or subcontractors.

Printed in the United States of America. To obtain copies of this document, contact: Document Control Services, P.O. Box 950, Mailstop H6-08, Richland WA 99352, Phone (509) 372.2420; Fax (509) 376-4989.
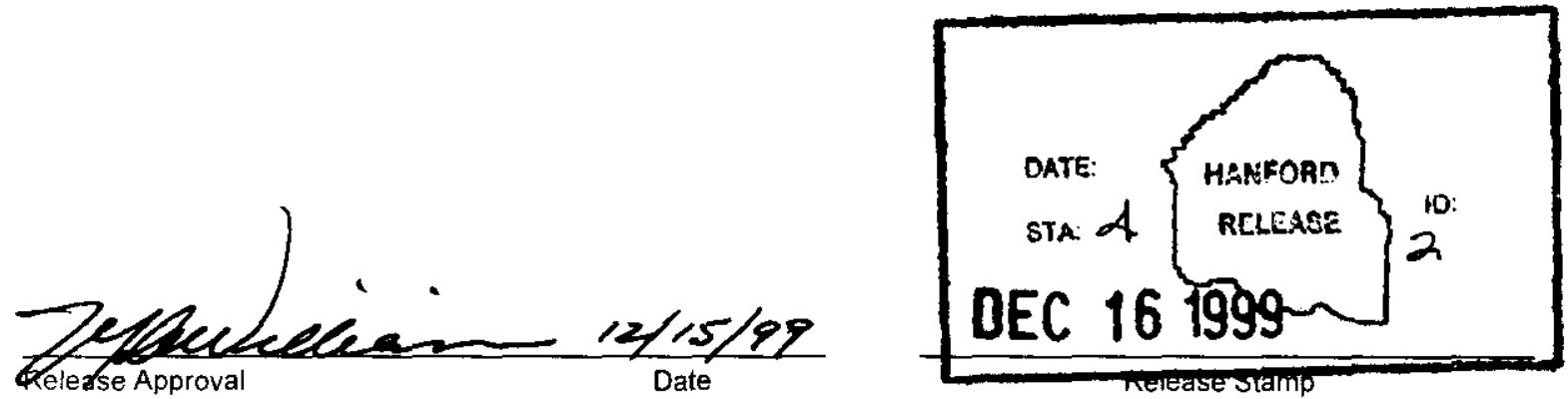

Approved For Public Release 


\title{
Functions, Requirements, and Specifications for Replacement of the Computer Automated Surveillance System (CASS)
}

\author{
RPP-5366 \\ Revision 0 \\ Approval Designator: E,S,Q
}

Prepared by:

D. K. Douka, Parsons Infrastructure \& Technology, Richland WA

J. J. Shaffer III, Parsons Infrastructure \& Technology, Richland WA

\begin{tabular}{|c|c|c|c|}
\hline \multicolumn{2}{|c|}{ Approved for release by: } & Signature & Date \\
\hline C.C. Scaief III & Design Authority & Signature On file, EDT 628217 & $11 / 22 / 1999$ \\
\hline M. J. Holm & Cognizant Engineer & Signature On file, EDT 628217 & $11 / 22 / 1999$ \\
\hline D. G. Baide & $\begin{array}{l}\text { Manager, East Area Double } \\
\text { Shell Tank Engineering }\end{array}$ & Signature On file, EDT 628217 & $12 / 15 / 1999$ \\
\hline J. B. Jech & $\begin{array}{l}\text { Operations Configuration } \\
\text { Management }\end{array}$ & Signature On file, EDT 628217 & $11 / 22 / 1999$ \\
\hline C. E. Shipler & $\begin{array}{l}\text { Manager, Operations } \\
\text { Configuration Management }\end{array}$ & Signature On file, EDT 628217 & $11 / 22 / 1999$ \\
\hline R. P. Tucker & $\begin{array}{l}\text { Deputy Operations Manager, } \\
\text { Tank Farm Operations }\end{array}$ & Signature On file, EDT 628217 & $11 / 23 / 1999$ \\
\hline J. H. Huber & $\begin{array}{l}\text { Design Authority, Single Shell } \\
\text { Tank Engineering }\end{array}$ & Signature On file, EDT 628217 & $11 / 23 / 1999$ \\
\hline R. S. Nicholson & AN Farm Design Authority & Signature On file, EDT 628217 & $12 / 14 / 1999$ \\
\hline C. J. Hopkins & $\begin{array}{l}\text { Manager, Nuclear Regulatory } \\
\text { Compliance Support }\end{array}$ & Signature On file, EDT 628217 & $12 / 15 / 1999$ \\
\hline W. L. Adams & LMHC Quality Assurance & Signature On file, EDT 628217 & $11 / 22 / 1999$ \\
\hline P. C. Miller & $\begin{array}{l}\text { LMHC Environmental } \\
\text { Compliance }\end{array}$ & Signature On file, EDT 628217 & $11 / 23 / 1999$ \\
\hline
\end{tabular}

EFFECTIVE RELEASE DATE: December 17, 1999

Lockheed Martin Hanford Company

Richland, Washington 


\section{Table of Contents}

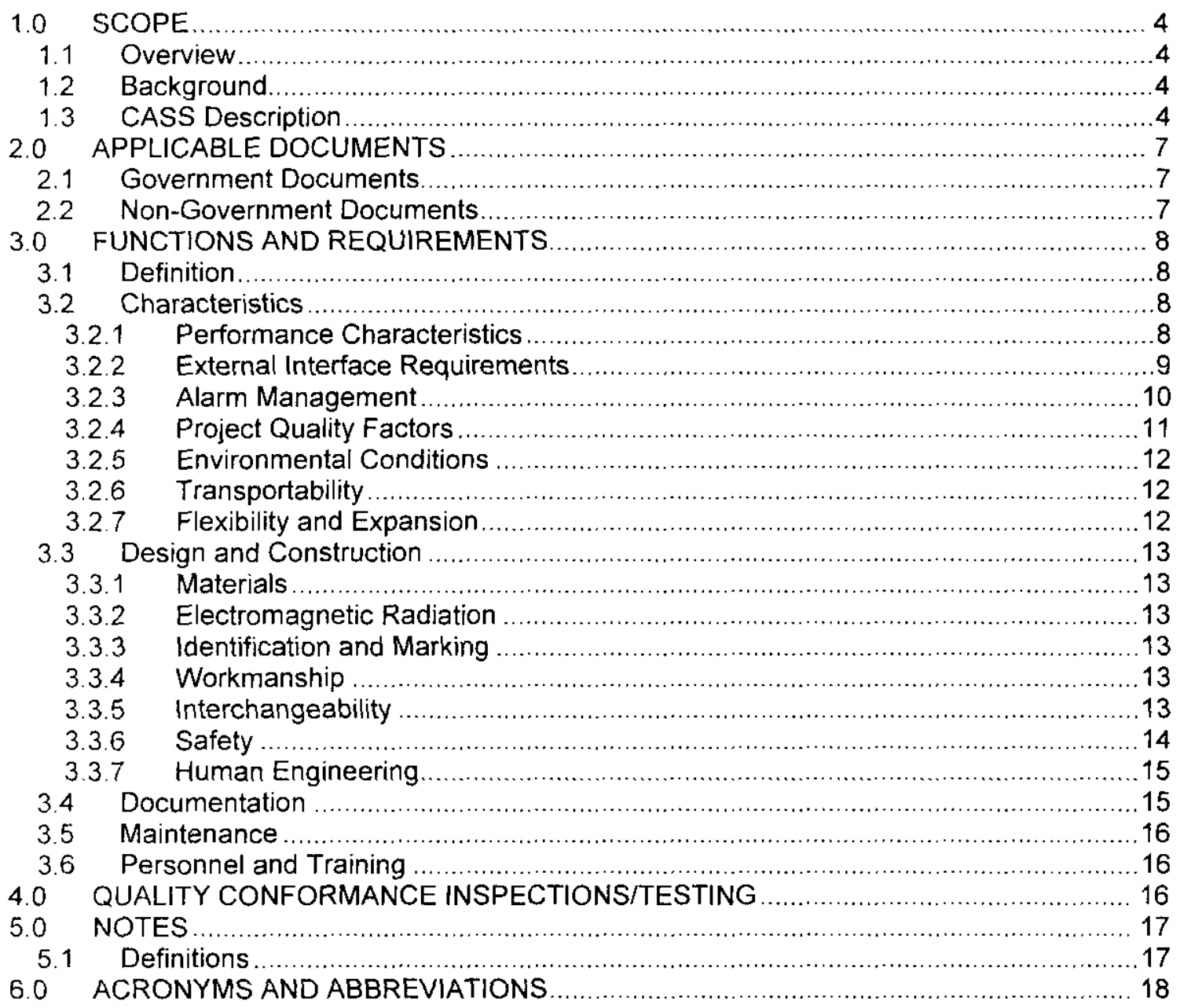




\section{LIST OF TABLES}

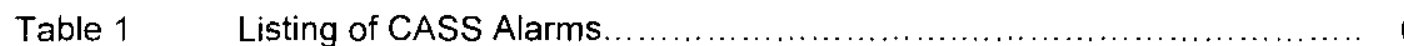

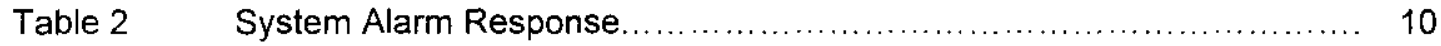

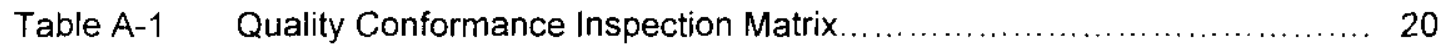

Table B-1 Identification and Safety Classification of AN - Tank Farm Alarms......... 32

Table B-2 Identification and Safety Classification of AW - Tank Farm Alarms ........ 36

Table B-3 Identification and Safety Classification of AP - Tank Farm Alarms......... 40

Table B-4 Identification and Safety Classification of A - Tank Farm Alarms........... 46

Table B-5 Identification and Safety Classification of SX - Tank Farm Alarms......... 49

Table B-6 Identification and Safety Classification of S - Tank Farm Alarms.......... 50

Table B-7 Identification and Safety Classification of CR - Tank Farm Alarms......... 52

Table B-8 Identification and Safety Classification of AR - Tank Farm Alarms......... 53

Table B-9 Identification and Safety Classification of BY - Tank Farm Alarms......... 54

Table B-10 Identification and Safety Classification of T - Tank Farm Alarms........... 55

Table B-11 Identification and Safety Classification of SY - Tank Farm Alarms......... 56 


\subsection{SCOPE}

\subsection{Overview}

This functions, requirements and specifications document defines the baseline requirements and criteria for the design, purchase, fabrication, construction, installation, and operation of the system to replace the Computer Automated Surveillance System (CASS) alarm monitoring.

\subsection{Background}

The CASS, as described in the Tank Farms Safety Analysis Report, HNF-SD-WM-067, Rev 1, was designed to provide central, computerized surveillance of the Hanford waste storage tanks and their associated facilities. CASS consisted of six remote computers that received temperature, alarms, raw water usage, and liquid level signals. The remote computers communicated with the Central Surveillance Computer (CSC) located in Building $2750 \mathrm{E}$ in the $200 \mathrm{E}$ Area. CASS provided no controls, interlocks, or automatic action based on the signals it received. An operator at the central CASS/TMACS Facility, manned on a 24-hour basis, monitored the system and advised field operators of alarm conditions. The CASS was developed in a closed architecture and the system was maintained beyond its life expectancy causing the hardware and software to become obsolete. An Unreviewed Safety Question (USQ-TF-98-0829) Screening and Determination found that CASS could be removed from service since alternative monitoring means (manual monitoring and data entry) were available to meet surveillance requirements. The CASS was officially retired on February 25, 1999.

\subsection{CASS System Description}

The CASS provided tank farm monitoring. Field detection and monitoring instrumentation systems were essentially the same for all individual tanks within the tank farms. Instruments sent data to microcomputers in the appropriate instrument buildings. All measured values were converted to electrical signals before transmission to CASS computers. Most monitored data was transmitted automatically to the CASS; however, some data was measured and recorded manually and maintained at each farm without input to CASS.

Signals were monitored and displayed on panel boards within the associated instrument building. Each tank had an associated local panel board, transmitter enclosure, and assigned portion of the pressure switch rack. Some signais were transmitted to the 242-A Evaporator control room for the 200 East Area, and to the 242-S control room for the 200 West Area, as well as to the DST instrument buildings. 
Typical process parameters continuously monitored by the CASS at time of decommissioning:

- Remote computer communication failures

- Leak detection pit alarms (high radiation, high liquid level)

- Tank pressure alarms (high pressure and vacuum)

- Leak detectors on tank annulus floor

- Exhaust fan failure alarms

- Radiation detection units (annulus exhaust CAMs, HVAC exhaust stack CAMs, instrument building panel alarms)

- Process line, encasement, process pit, and cleanout box leak detectors

- Failure of liquid level monitoring equipment

\section{Analog parameters originally scanned by CASS on an hourly basis:}

- Actual liquid level measurements

- Temperature

Note: Analog signals originally monitored by CASS have been transferred to an alternate system. The remaining signals to be moved to the replacement system are comprised only of alarm (discrete) points.

Instrument panel boards displayed or recorded the monitored process conditions in various areas of the tank farms.

Separate CASS program files were kept for data categories and were held in the program's 32day historical file. Data was transferred daily to the permanent retention file. The CASS reports contained information either received automatically or manually entered through a computer terminal. A few readings (selected liquid level and weight factor) were not CASS files. These readings were manually measured on each shift and then manually recorded and retained by tank farm and evaporator process control personnel. Reports were generated on standardized report forms. Each tank farm could select and customize the data contained in the reports. 


\section{TABLE 1 \\ LISTING OF CASS ALARMS}

Table 1 is a current estimate of the number of CASS alarms that are to be transferred. Alarm Equipment ID, Activating Device, CASS ID, Parameter Description, CASS Message, and Safety Classification are contained in Appendix B tables.

\begin{tabular}{|c|l|c|}
\hline Substation & \multicolumn{1}{|c|}{ Building } & Number of Alarms \\
\hline & $241-\mathrm{A}-271$ & 46 \\
$\mathrm{~A}$ & $204-\mathrm{AR}$ & 12 \\
& $241-\mathrm{AW}-271$ & 46 \\
& $241-\mathrm{AP}-271$ & 64 \\
& $242-\mathrm{A}$ & 68 \\
\hline $\mathrm{B}$ & $241-\mathrm{BY}-254$ & 12 \\
\hline C & $241-\mathrm{CR}-271$ & 6 \\
& $241-\mathrm{AN}-271$ & 59 \\
\hline \multirow{3}{*}{$\mathrm{S}$} & $241-\mathrm{SX}-271$ & 13 \\
& $242-\mathrm{S}$ & 35 \\
\hline T & $241-\mathrm{SY}-271$ & 22 \\
\hline U & $242-\mathrm{T}$ & 17 \\
\hline TOTAL & $241-\mathrm{U}-271$ & 0 \\
\hline
\end{tabular}

NOTE: All above CASS alarm inputs were monitored in 2750E. 


\subsection{APPLICABLE DOCUMENTS}

Design requirements applicable to The System come from government and non-government source documents and various codes and standards. Each document (of the exact section identified) is invoked by one or more requirements of this specification and represents a part of this specification to the extent specified.

\subsection{Government Documents}

DOE Order 6430.1A, 1989, General Design Criteria

DOE Order 4330.4B, 1994, Maintenance Management Program, U.S. Department of Energy

MIL-STD-1472E, Human Engineering Design Criteria for Military systems, Equipment and Facilities, U.S. Department of Defense

UCRL-15673, 1985, Human factors Design Guidelines for Maintainability of DOE Nuclear Facilities

NUREG 0700, Rev. 1, Guidelines for Control Room Design Reviews, Nuclear Regulatory Commission Regulatory Guide

\subsection{Non-Government Documents}

LMH-SD-WM-SFR-006, Draft, System Functional Requirements: Tank Monitoring And Control System (TMACS) Software Project

LMH-PRO-097, Rev 0, Engineering Design and Evaluation

LMH-PRO-222, Rev. 1, Quality Assurance Records

LMH-PRO-224, Rev. 1, Document Control

LMH-PRO-1819, Rev. 1, PHMC Engineering Requirements

HNF-IP-0842, Volume II, Section 6.1 Rev. 0, Tank Farm Operations Equipment Labeling

HNF-4211, Draft, Functions and Requirements for Tank Monitor And Control System (TMACS)

WHC-SD-WM-TI-671, Rev. 0, TMACS System Description

HNF-SD-WM-WP-344, Rev. 0, Computer Automated Surveillance System (CASS) Retirement Plan

HNF-SD-WM-SEL-040, Rev. 1, TWRS Facility Safety Equipment List

HNF-SD-WM-067, Rev. 1, Tank Farms Safety Analysis Report 
HNF-IP-0842, Vol. IV, Section 4.14, Rev. 2b, Tank farm Operations Equipment Labeling and Master Equipment List Control

PNNL-11107, Hanford Site Climatological Data Summary, 1995

FM, Approval Guide, Factory Mutual System

Unreviewed Safety Question Tracking No. TF-98-0829 rev. 1, Remove Computer Automated Surveillance System (CASS) from Operation

\subsection{FUNCTIONS AND REQUIREMENTS}

\subsection{Definition}

The CASS alarm monitoring replacement system (hereafter referred to as "the system") shall be capable of receiving field generated signals for approximately 400 discrete alarm input signals. The system shall only monitor inputs and will provide no control functions.

\subsection{Characteristics}

\subsubsection{Performance Characteristics}

\subsubsection{Alarm Processing}

3.2.1.1.1 The system shall be capable of receiving and processing approximately 400 alarm input signals, with capability to expand by up to $50 \%$ with no degradation in performance.

3.2.1.1.2 The system shall have the capability to enable or disable alarm processing for individual sensors.

Note: The above is currently accomplished by the System Administrator.

3.2.1.1.3 The system shall be capable of displaying sensor (alarm) states.

3.2.1.1.4 Discrete sensor states shall include:

- Alarm Condition

- Normal Condition

- $\quad$ Out of service 
3.2.1.1.5 The Operator shall be visually notified when an alarm changes state. As a minimum the notification shall contain:

- Sensor Description

- Sensor State

- Date/Time of change

3.2.1.1.6 The visual state change notification shall be persistent until the operator acknowledges the notification and the alarm returns to the normal state.

3.2.1.1.7 The Operator shall be audibly notified upon an alarm condition.

3.2.1.1.8 The audible alarm shall respond as listed in Table 2.

3.2.1.1.9 Each alarm shall have a color associated with each as listed in Table 2.

3.2.1.1.10 As a minimum, the system shall allow assignments of display colors as listed in Table 2.

3.2.1.1.11 Alarm state changes and operator acknowledgements shall be logged to an event recorder to provide a hard copy record and to a computer storage device.

3.2.1.1.12 The event recorder shall print alarm state changes and operator acknowledgements in the same order as the events occurred.

3.2.1.1.13 Each event printed shall include a date and time reference.

\subsubsection{External Interface Requirements}

3.2.2.1 The system shall be capable of fully communicating to remote shift operations with tank farm HMls via the HLAN.

3.2.2.2 The system shall be capable of communicating with field equipment for the purpose of monitoring discrete alarm conditions.

3.2.2.3 The system shall be capable of polling selected discrete points at least once per minute. 


\subsubsection{Alarm Management}

The system shall perform the following alarm management functions

3.2.3.1 Display alarm status and reset for any discrete point.

3.2.3.2 Display system alarm for communication errors and unsuccessful polls.

3.2.3.3 Alarm information on the alarm summary display shall include

- Date

- Time

- Tag Descriptor

- Alarm status with acknowledgement

3.2.3.4 Audible alarm is silenced upon alarm acknowledgement.

3.2.3.5 Alarm status shall be displayed on a monitor to provide the Operator with a graphic of the local annunciator panel, a process related graphic (tank farm layout), or both.

3.2.3.6 The system shall log an operator's acknowledgement and alarm return to normal.

3.2.3.7 All system alarms shall respond in the manner listed in Table 2:

TABLE 2

\section{SYSTEM ALARM RESPONSE}

\begin{tabular}{|l|l|}
\hline \multicolumn{1}{|c|}{ EVENT } & \multicolumn{1}{c|}{ SYSTEM ALARM } \\
\hline Event initiates an enabled alarm & Red or yellow flashing symbol (NOTE 1) \\
\hline Operator acknowledges alarm at system & Non-flashing red or yellow symbol \\
\hline Event alarm recovers prior to acknowledge & Green flashing symbol \\
\hline Event alarm recovers after acknowledge & Non-flashing green symbol (NOTE 2) \\
\hline $\begin{array}{l}\text { Non-normal operating mode (i.e. loss of } \\
\text { communication, Enraf in Non-operational } \\
\text { mode) }\end{array}$ & White symbol (NOTE 3) \\
\hline System Administrator disables alarm & Gray symbol (NOTE 4) \\
\hline
\end{tabular}


Note 1: An alarm condition is associated with either red or yellow. A red alarm indicates the highest priority while yellow indicates an alert point. Yellow does not require immediate operator action.

Note 2: The system alarm returns to steady green after the system scans the input and processes the signal. The system scan rate determines how quickly the system responds after the alarm condition clears.

Note 3: A white symbol indicates communications have been lost with the field equipment or the signal is out of range. White is technically not an indicator of an alarm but rather indicates status of sensor is unknown and may require an Operator response.

Associated field alarms, if applicable, may continue to operate.

Note 4: Gray indicates the decision has been made not to process the alarm input to the system. In this case only the field alarms, if applicable, will continue to function.

\subsubsection{Project Quality Factors}

\subsubsection{Maintainability}

3.2.4.1.1 The design of equipment shall incorporate the objective of efficient maintainability The testing and maintenance of the system and its restoration to operational effectiveness shall be achieved at minimum cost with a minimum level of support services. The UCRL-15673, Human Factors Design Guidelines for Maintainability of DOE Nuclear Facilities, and DOE Order 4330.4B, Maintenance Management Program shall be considered for system design.

\subsubsection{Design Life}

3.2.4.2.1 The system shall be designed to operate for a minimum of 35 years.

Note: It is expected that failures will occur over this period which will require equipment replacement and that future technological advances may dictate additional replacements to enhance system operation/reliability.

\subsubsection{Reliability}

3.2.4.3.1 Equipment shall be designed to function reliably for at least three years before repair/replacement.

3.2.4.3.2 Systems and associated instrumentation and controls shall be designed, where practical, to provide for the detection of faults to systems, structures, and components as necessary in order to minimize the risks associated with faulty operation to plant, personnel, and environment. 


\subsubsection{Environmental Conditions}

3.2.5.1 Induced Environments

3.2.5.1.1 Radiation Tolerance

3.2.5.1.1.1 This section is not applicable. The system will be located in a controlled area for normal daily monitoring.

3.2.5.2 Natural Environments

3.2.5.2.1 All equipment will be located inside climate controlled buildings and will not be subject to outside environmental conditions. Equipment shall be designed to withstand the following conditions:

- Relative Humidity:

Highest monthly mean relative humidity: $\quad 80 \%$

Daily change: $\quad 30 \%$

- Temperature:

Inside temperature range: $\quad 10^{\circ} \mathrm{C}$ to $35^{\circ} \mathrm{C}\left(50^{\circ} \mathrm{F}\right.$ to $\left.95^{\circ} \mathrm{F}\right)$

Outside ambient air temperature range: $-32^{\circ} \mathrm{C}$ to $46^{\circ} \mathrm{C}\left(-27^{\circ} \mathrm{F}\right.$ to $\left.115^{\circ} \mathrm{F}\right)$

\subsubsection{Transportability}

3.2.6.1 This section is not applicable

\subsubsection{Flexibility and Expansion}

3.2.7.1 The system shall be of an open-ended design allowing expansion of future project requirements. 


\subsection{Design and Construction}

\subsubsection{Materials}

3.3.1.1 Telecommunication devices, alarm devices, data processing equipment, and telephone modem stations shall be housed in fire-resistant structures and located outside areas subject to explosion, fire, flood, chemical fumes, excessive dust, vibration, dampness, high noise levels, and high electrical interference.

3.3.1.2 Electrical materials and equipment shall be UL or FM tested, with label attached, for the purpose intended, whenever such products are available. Where there are no UL or FM listed products of the type required, testing and certification by another nationally recognized testing agency may be acceptable.

\subsubsection{Electromagnetic Radiation}

The design shall consider the effects of electromagnetic radiation on the signal conditioning equipment.

\subsubsection{Identification and Marking}

3.3.3.1 New equipment and/or modifications to existing equipment shall be labeled in a standardized format in accordance with HNF-IP-0842, Volume II, Section 6.1, Tank Farm Operations Equipment Labeling.

\subsubsection{Workmanship}

This section is not applicable

\subsubsection{Interchangeability}

This section is not applicable 


\subsubsection{Safety}

\subsubsection{Nuclear Safety}

\subsection{Safety Classification}

Note: Refer to Section 5.1 for safety classification definitions

Note: The safety classifications (GS, SS, SC) of equipment providing inputs to the CASS replacement system are listed in Appendix B tables. The determination of Safety Classifications was made by the appropriate Technical Authority, Design Authorities, and Operations, and with reference to HNF-SD-WM-SEL-040, TWRS Facility Safety Equipment List. New or modified equipment that is required to support safety class equipment shall meet the following requirements.

3.3.6.1.1.1 Safety class instrumentation and control systems shall provide audible and visual alarms.

3.3.6.1.1.2 The design of safety class instrumentation and controls shall provide suitable redundancy and diversity to ensure that safety functions can be completed, when required, and that no single failure will result in the loss of the protective functions.

3.3.6.1.1.3 The design of safety class instrumentation and control systems shall provide for the periodic in-place testing and calibration of instrument channels and interlocks.

3.3.6.2 Industrial and Occupational Safety

This section is not applicable

\subsubsection{Natural Phenomena Hazards}

3.3.6.3.1 The replacement system is not required to perform any safety function during or after the occurrence of extreme natural phenomena events (e.g., earthquake, high wind, tornado, snow fall, ash fall, etc). The system shall be designed to meet requirements of LMH-PRO-097 for performance category one. 


\subsubsection{Human Engineering}

3.3.7.1 Warning and alarm systems shall be designed, installed, and tested to ensure they can be heard in the ambient conditions of the area for which they are intended.

3.3.7.2 Displays shall provide the information about system status and parameter values which is needed to meet task requirements. Continuous status, rather than ondemand information, shall be displayed for important parameters. Displays shall indicate whether they reflect demand or actual status.

3.3.7.3 Each display device, including meters, CRTs, LCDs, consoles, and other electronic or mechanical media shall be formatted and designed to ensure both the display and display content are readable, understandable, and accessible.

3.3.7.4 Failure of a display of any type shall easily be recognized and shall not affect equipment or system performance unless alternate means exist to accomplish system performance.

3.3.7.5 Warning and annunciator systems shall alert personnel to problems or abnormal conditions and shall provide sufficient time to respond appropriately to the problem. General warning guidelines are found in MIL-STD-1472E, Section 5.3. for the special case of control room annunciators, see NUREG 0700 , Section 6.3. for auditory signal guidelines see NUREG 0700, Section 6.2.

\subsection{Documentation}

3.4.1 Records, documents, and drawing control pertinent to design functions shall be in accordance with LMH-PRO-222, and LMH-PRO-224. Drafting standards for drawings and interface control shall be in accordance with LMH-PRO-1819.

3.4.2 Operations and maintenance drawings (as-built essential drawings) shall be prepared as system master drawings showing as-built configuration changes in accordance with HNF-IP-0842, Volume IV, Section 4.14.

3.4.3 A Master Equipment List (MEL) consisting of an electronic database for SSCs shall be generated in accordance with HNF-IP-0842, Volume IV, Section 4.14. The MEL shall contain such information as unique equipment labels, drawing references, procedures, vendor information, safety classifications, nameplate data, etc. 


\subsection{Maintenance}

3.5.1 The system design shall provide for routine maintenance, repair, or replacement of equipment subject to failure. SSC shall be designed to allow inspection, maintenance, and testing to ensure their continued functioning, readiness for operation, and accuracy.

3.5.2 Testing performed after turnover, such as calibrations, functional tests, etc. shall be performed in accordance with existing applicable RPP procedures.

\subsection{Personnel and Training}

3.6.1 Personnel assigned to operate or maintain the system shall be trained for the tasks for which they will perform.

\subsection{QUALITY CONFORMANCE INSPECTIONS/TESTING}

4.1 Inspections shall be performed on system hardware representative of the approved production design for the purposes of verifying that the design meets the requirements of this specification, subject to the design verification procedure identified in $\mathrm{LMH}$ PRO-1819, Section 2.9.1. Inspection of the system design to assure compliance with the requirements of Section 3 shall be by examination, demonstration, test, and/or analysis, at level of assembly defined in Appendix A. Definitions of examination, demonstration, test, and analysis are as follows:

4.1.1 Examination is an element of inspection consisting of investigation without the use of special laboratory equipment or procedures to determine compliance with requirements. An acceptable method is through design verification.

4.1.2 Demonstration is an element of inspection that is limited to readily observable functional operation to determine compliance with requirements. This element of inspection does not require use of special equipment or sophisticated instrumentation.

4.1.3 Test is an element of inspection that employs technical means including, but not limited to, the evaluation of functional characteristics by use of special equipment or instrumentation, simulation techniques, and the application of established principles and procedures to determine compliance with requirements. The analysis of data derived from test is an integral part of this inspection.

4.1.4 Analysis is an element of inspection, taking the form of the processing of accumulated results and conclusions, intended to provide proof that verification of a requirement has been accomplished. The analytical results may be comprised of a compilation of interpretation of existing information or derived from lower level examination, tests, demonstrations, or analyses. An acceptable method through design verification. 
4.2 Field verification of System performance/design features and acceptance inspection of construction is called-out in Section 2.9.2 of LMH-PRO-1819. In addition to these inspections, which take place during the construction/turn-over lifecycle phase, the following requirements shall be implemented.

4.3 The following testing requirements apply to the qualification of the system and components. These test requirements correlate to the qualification of the design to the noted Section 3.0 requirements of this specification. Appendix A defines the method for verifying Section 3.0 requirements.

4.3.1 On-site acceptance testing shall be required for the system and components. Tests shall be specified to demonstrate that each function and important parameter is implemented

4.3.2 Initial testing shall be performed during or after installation by the responsible organization or company. Results shall be documented and provided to Operations/Maintenance upon request.

4.3.3 Prior to final turnover, the equipment shall be proven acceptable by Operations through the performance of Acceptance Test Procedures (ATPs). Tests shall be performed in accordance with WHC-SD-WM-ATP-023 and HNF-3967.

\subsection{NOTES}

\subsection{Definitions}

5.1.1 General Service (GS) SSC - Structures, systems, and components (SSC) not classified as either Safety Class or Safety Significant.

5.1.2 Safety Class (SC) SSC - A SSC that prevents or mitigates releases to the public that would otherwise exceed the offsite radiological risk guidelines, or to prevent a nuclear criticality. Those SSCs that support the safety function of a SC SSC are also SC.

5.1.3 Safety Significant (SS) SSC - A SSC that prevents or mitigates releases of radiological materials to onsite workers and toxic chemicals to the offsite public and onsite workers. Safety significant also describes worker safety SSCs that protect the facility worker from serious injury (or fatality) from hazards not controlled by institutional safety programs. Those SSCs that support the safety function of an SS SSC are also SS.

\subsubsection{Shall - Denotes a requirement.}




\subsection{ACRONYMS AND ABBREVIATIONS}

AC
ADP
ARP
ATP
DOE
CAM
CASS
CRT
CSC
DC
DST
FM
GS
HEPA
HMI
HVAC
I\&C
ID
I/O
IEEE
LCD
MEL
MIL-STD
ORP
OTP
SC
SEL
SS
SSC
SST
TMACS
TWRS
TSR
UL
UPS
WFD
ORR

\author{
Alternating Current \\ Automated Data Processing \\ Alarm Response Procedure \\ Acceptance Test Procedure \\ U.S. Department of Energy \\ Continuous Air Monitor \\ Computer Automated Surveillance System \\ Cathode Ray Tube \\ Central Surveillance Computer \\ Direct Current \\ Double Shell Tank \\ Factory Mutual \\ General Service \\ High Efficiency Particulate Air \\ Human Machine Interface \\ Heating, Ventilation and Air Conditioning \\ Instrument and Control \\ Identification \\ Input/Output \\ Institute of Electrical and Electronics Engineers \\ Liquid Crystal Display \\ Master Equipment List \\ Military Standard \\ Office of River Protection \\ Operational Test Procedure \\ Safety Class \\ Safety Equipment List \\ Safety Significant \\ Structures, Systems, and Components \\ Single Shell Tank \\ Tank Monitor And Control System \\ Tank Waste Remediation System \\ Technical Safety Requirements \\ Underwriters Laboratories \\ Uninterruptible Power Supply \\ Waste Feed Delivery
}




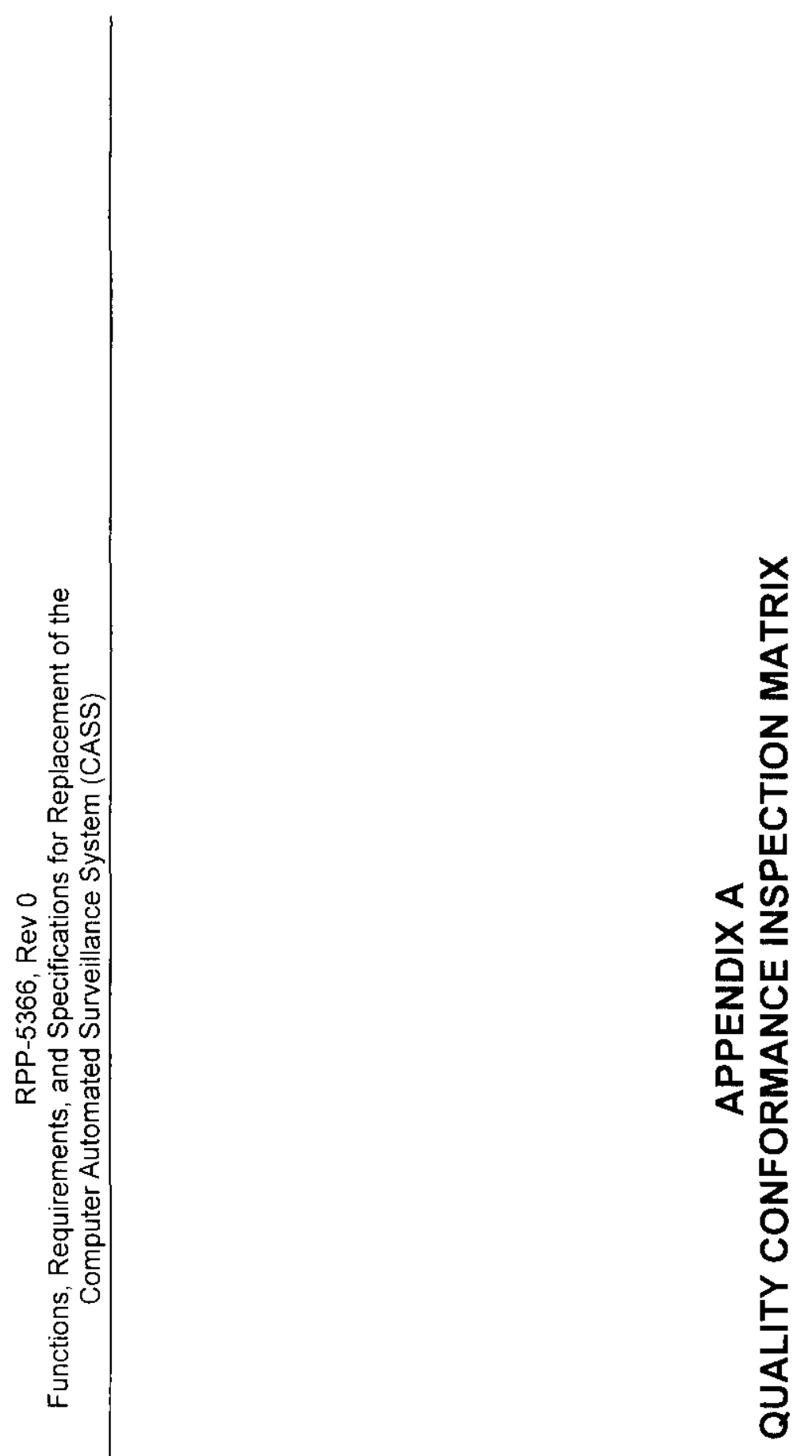




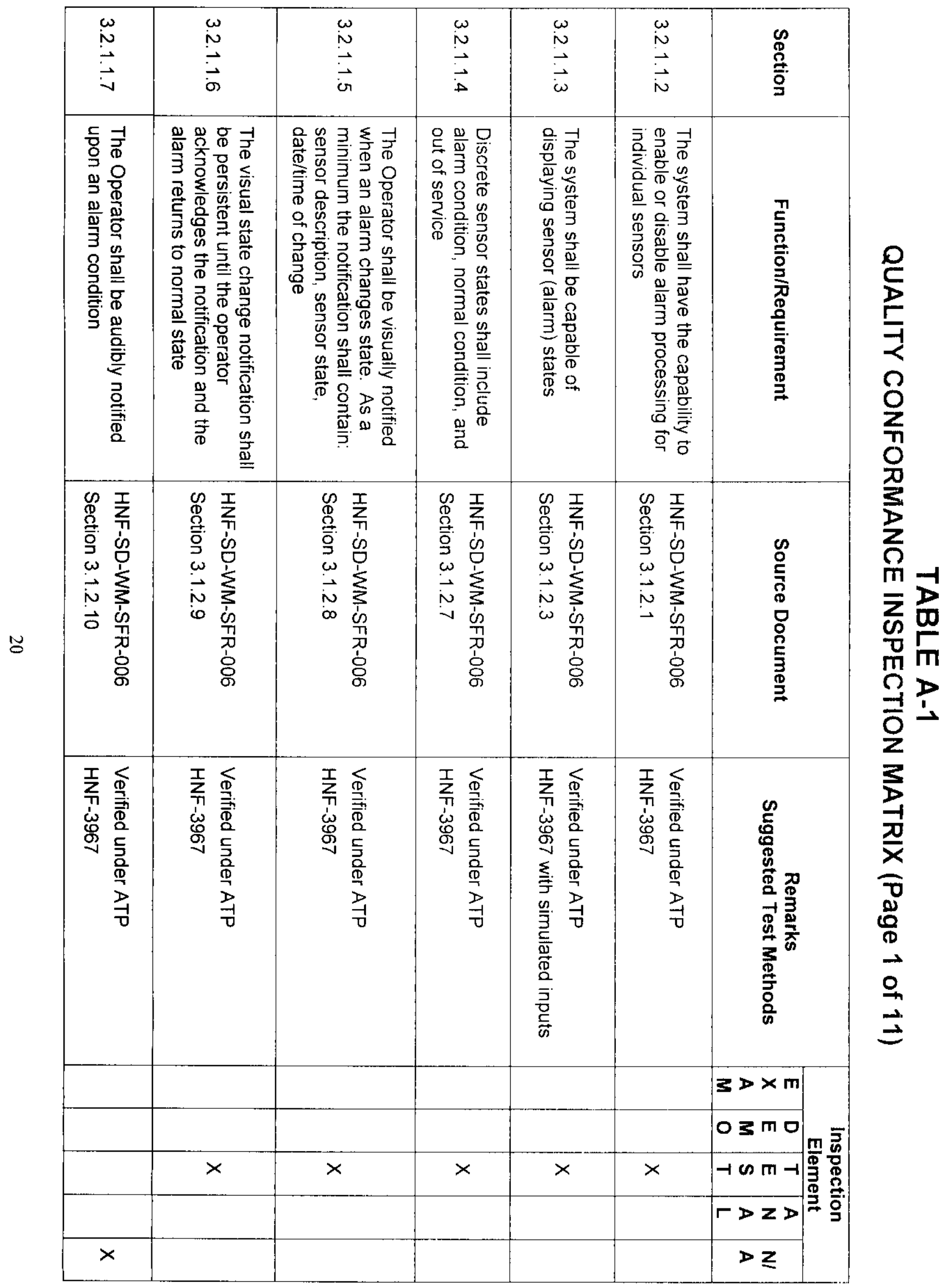



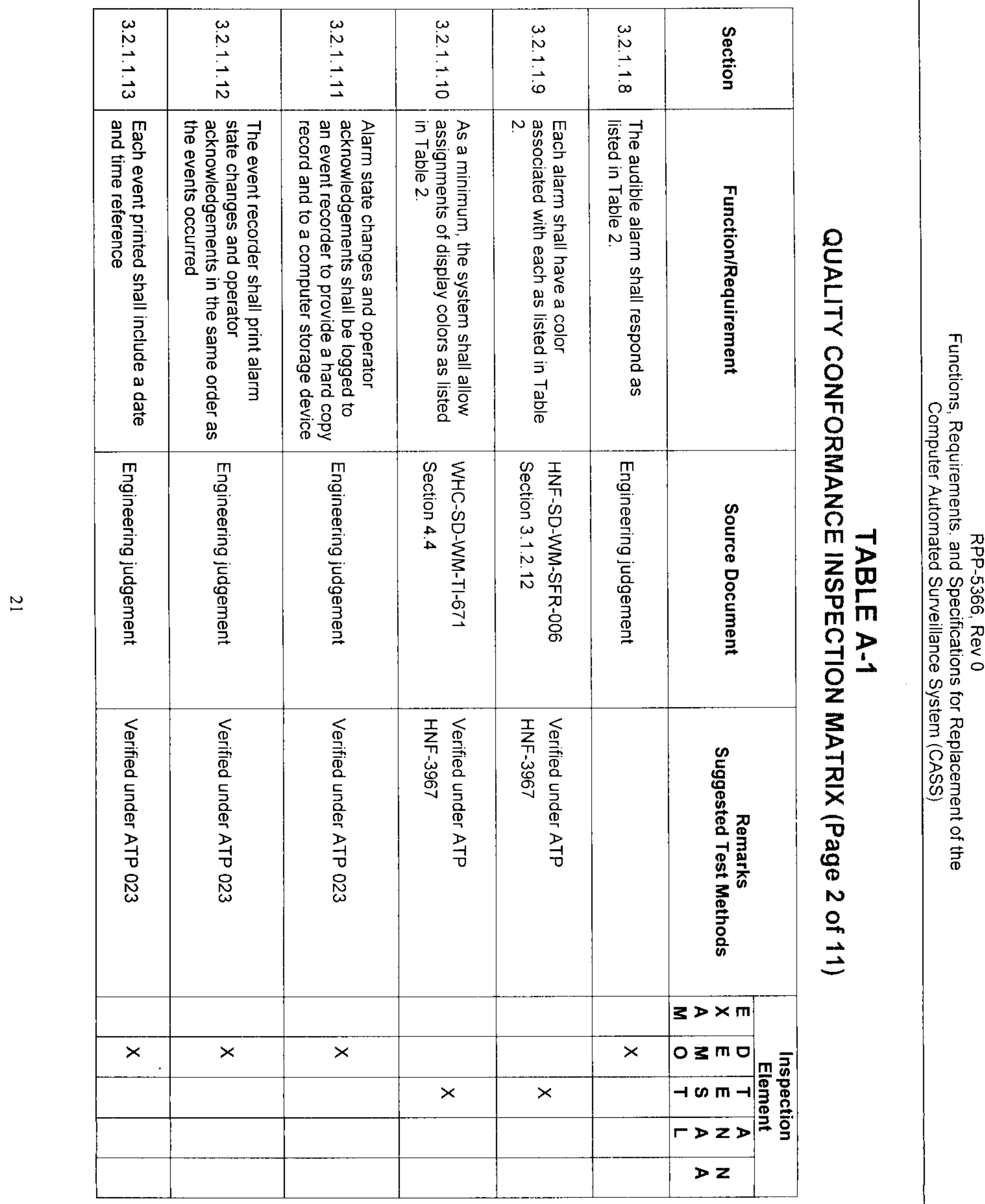


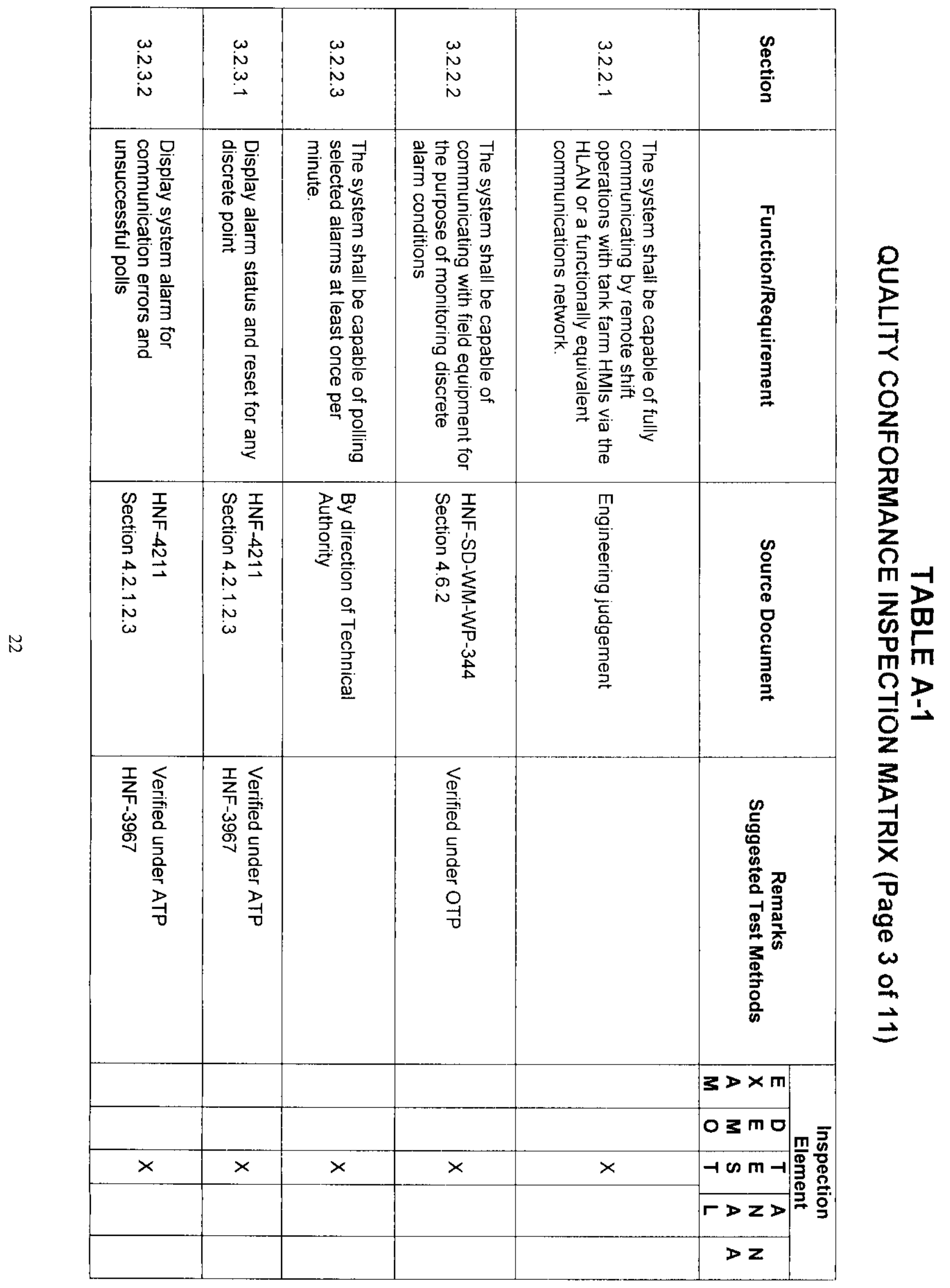




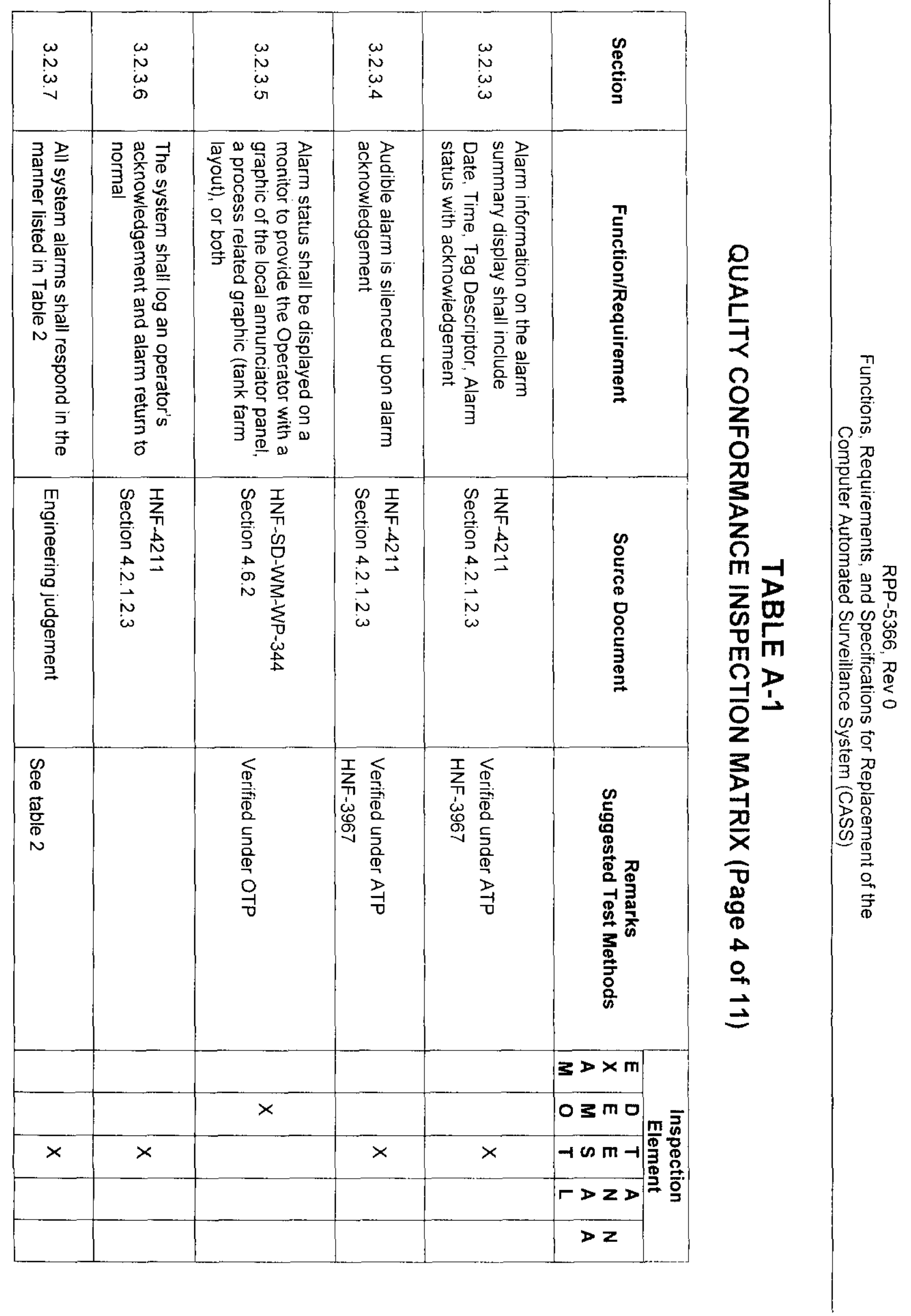




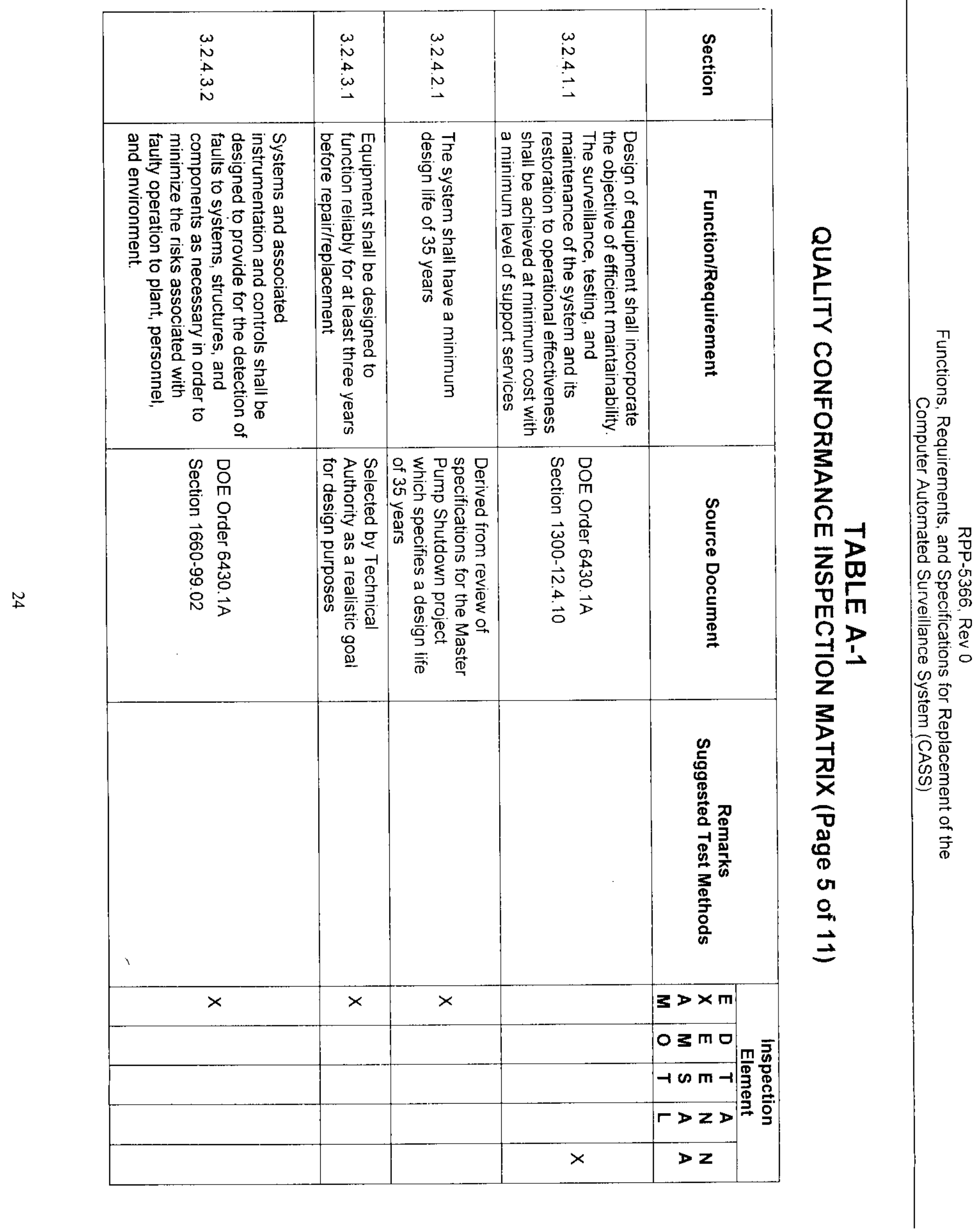




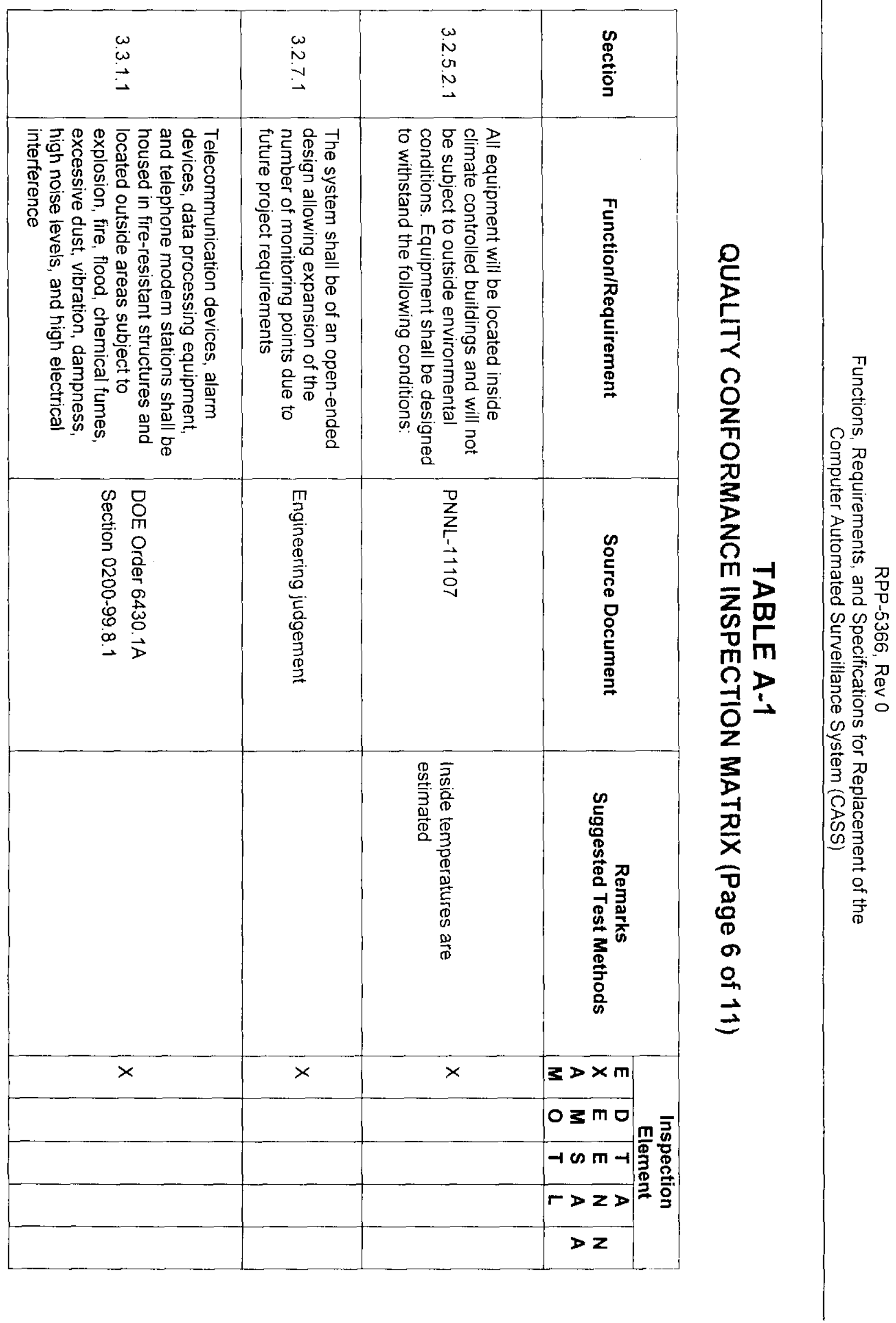




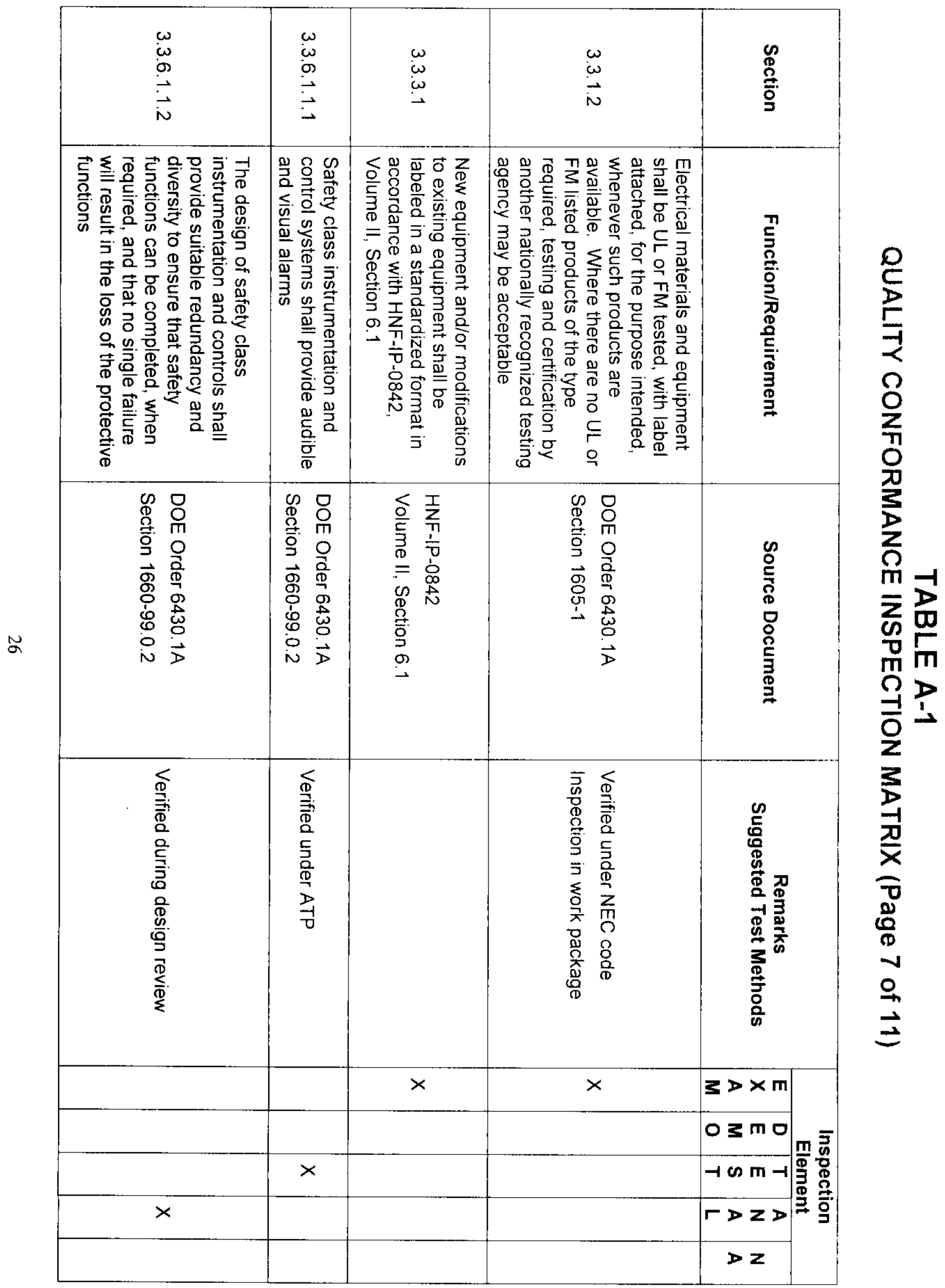




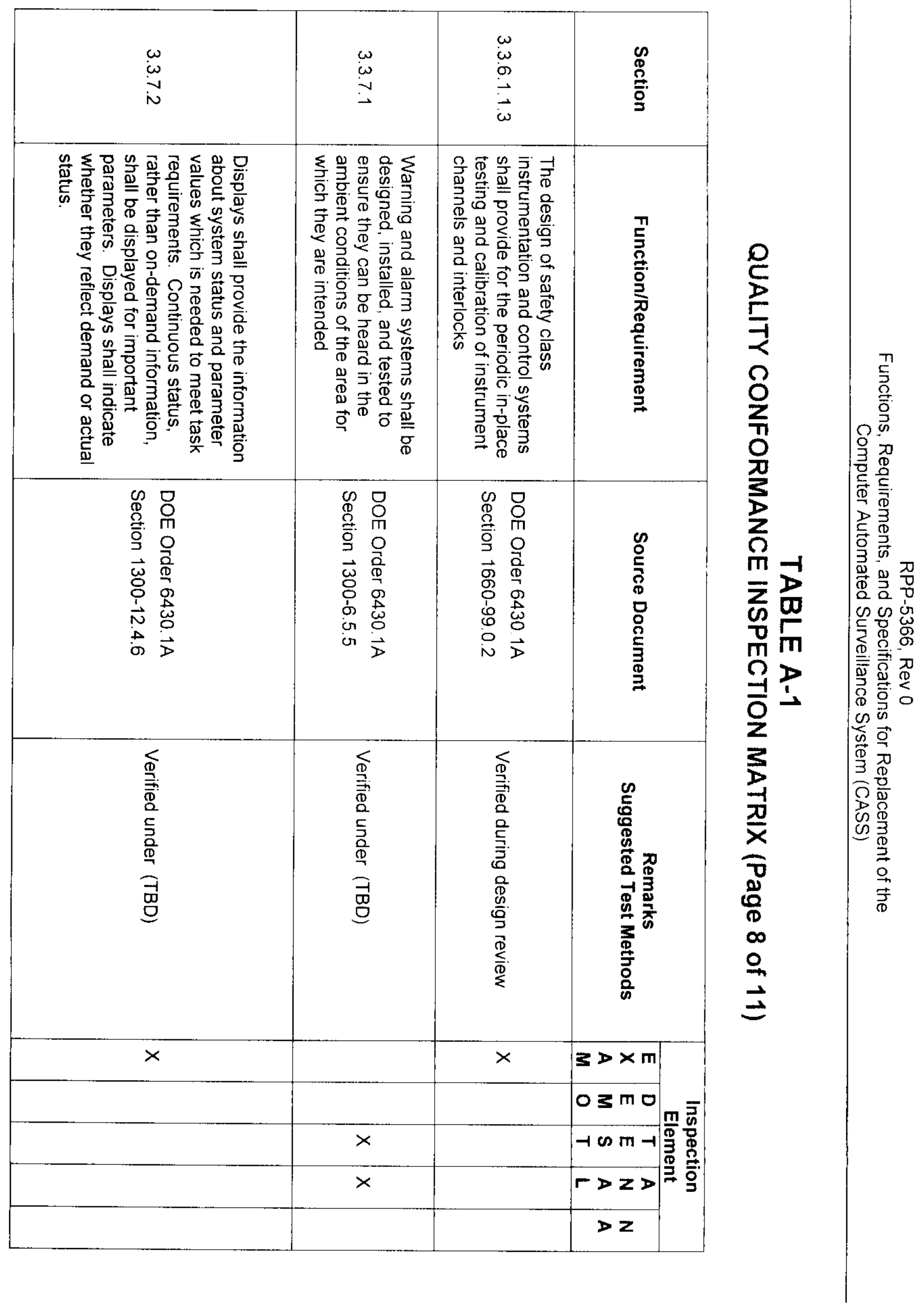




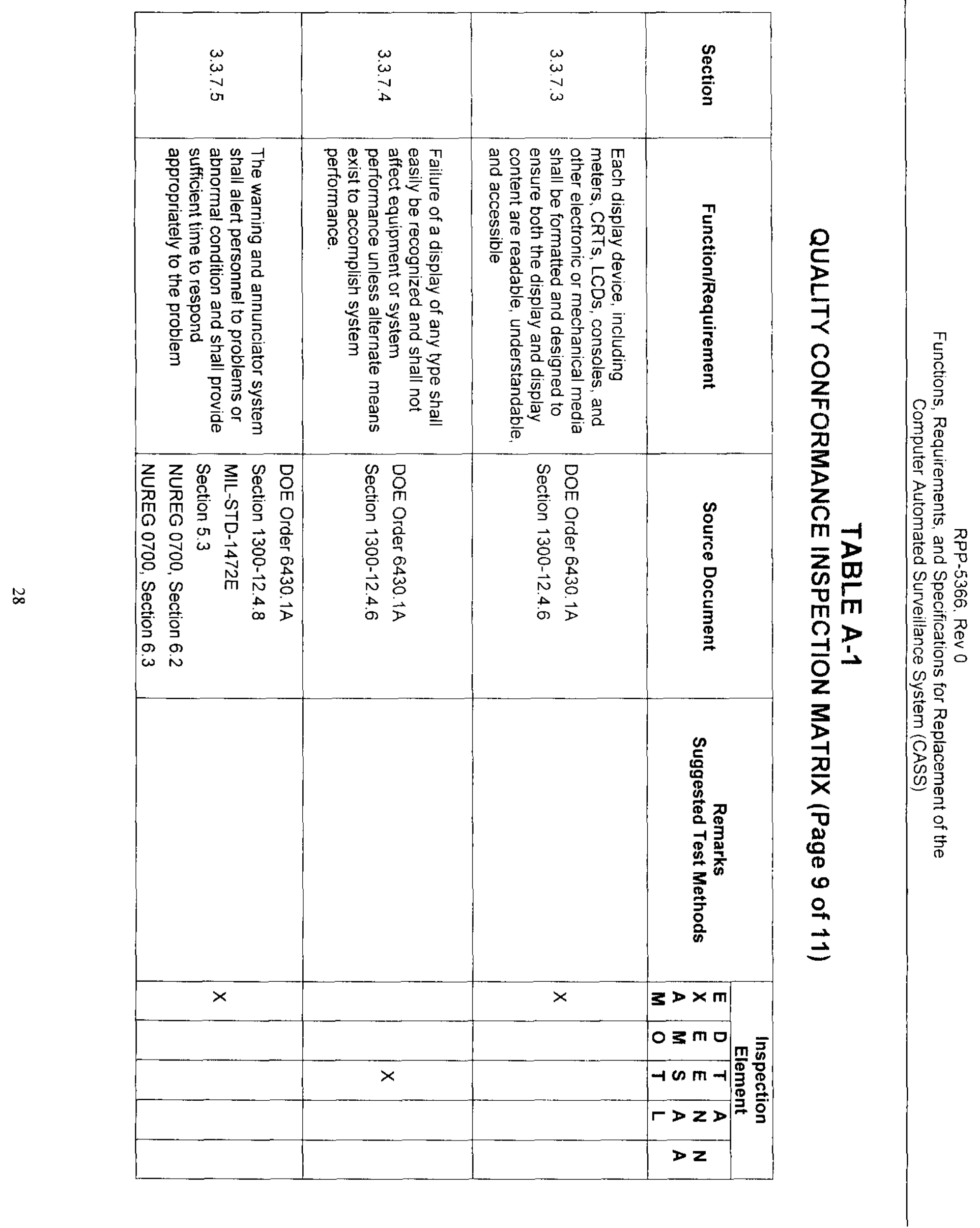




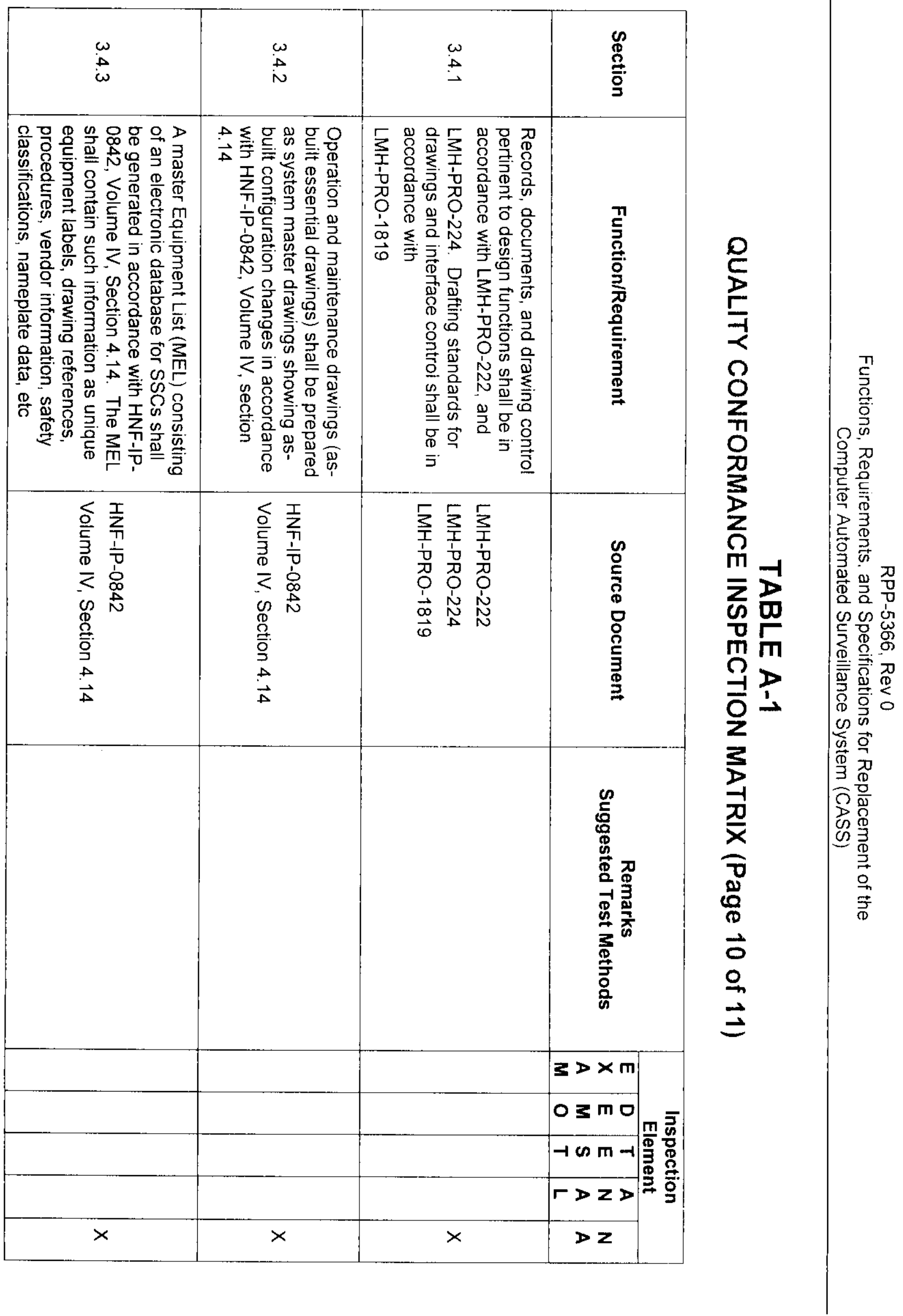




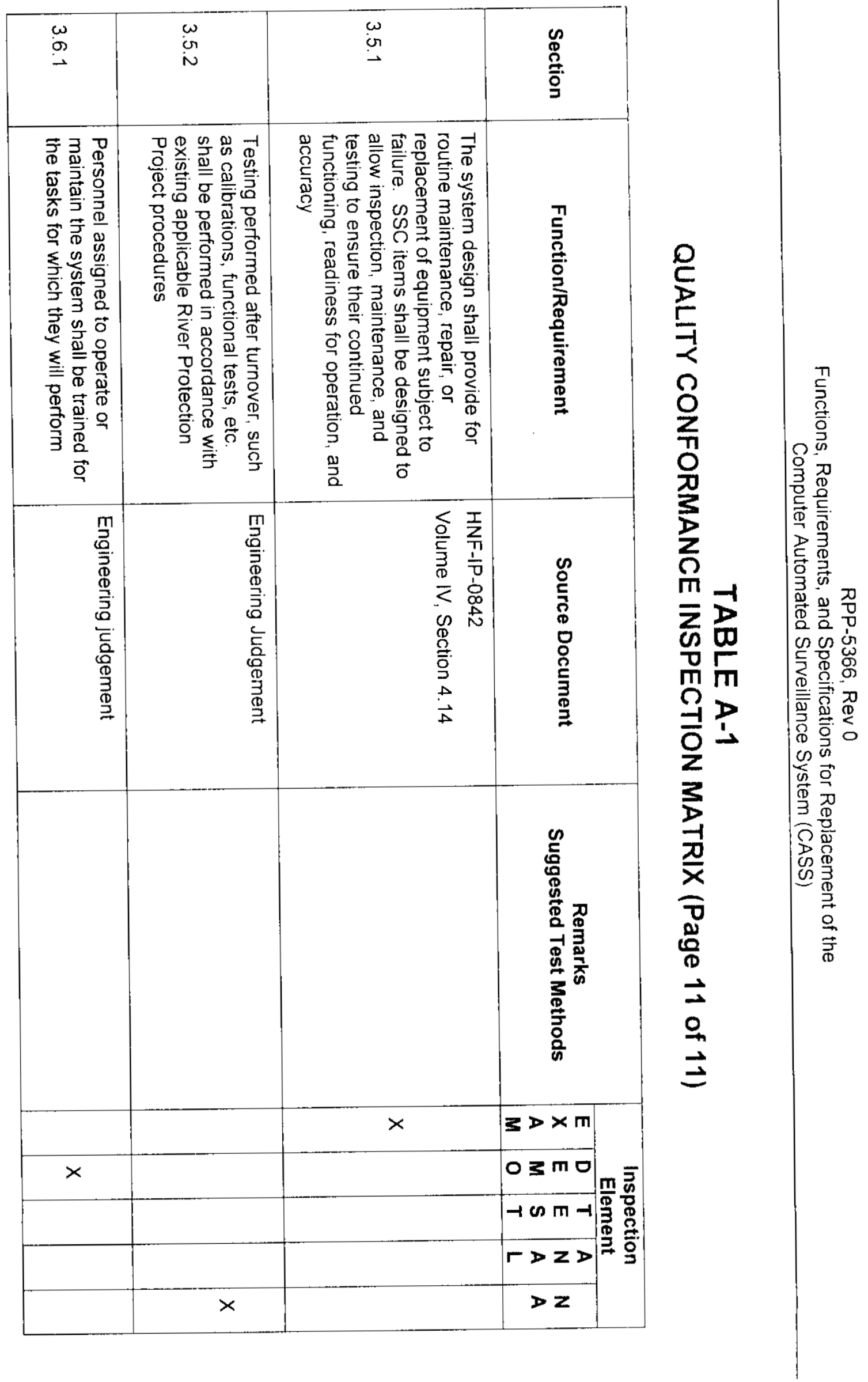




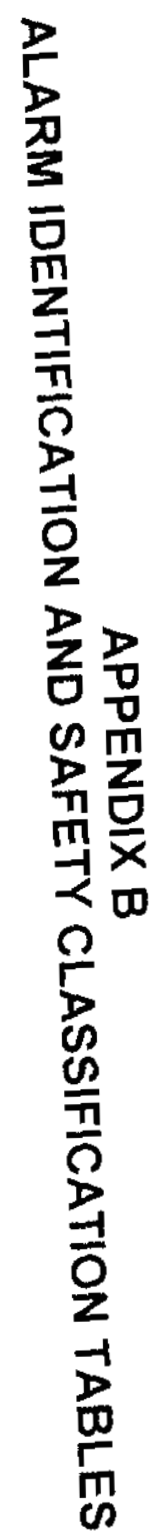




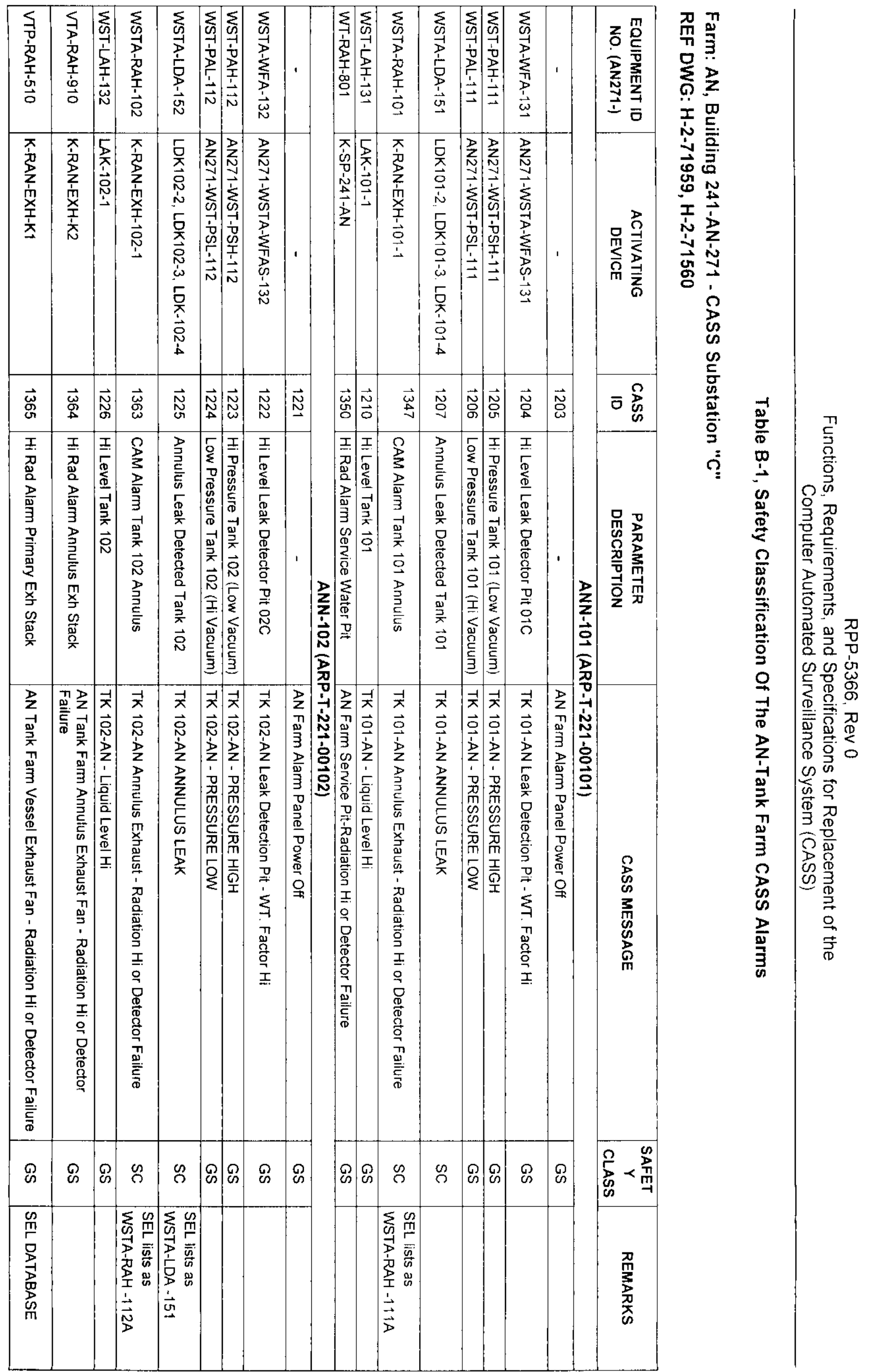




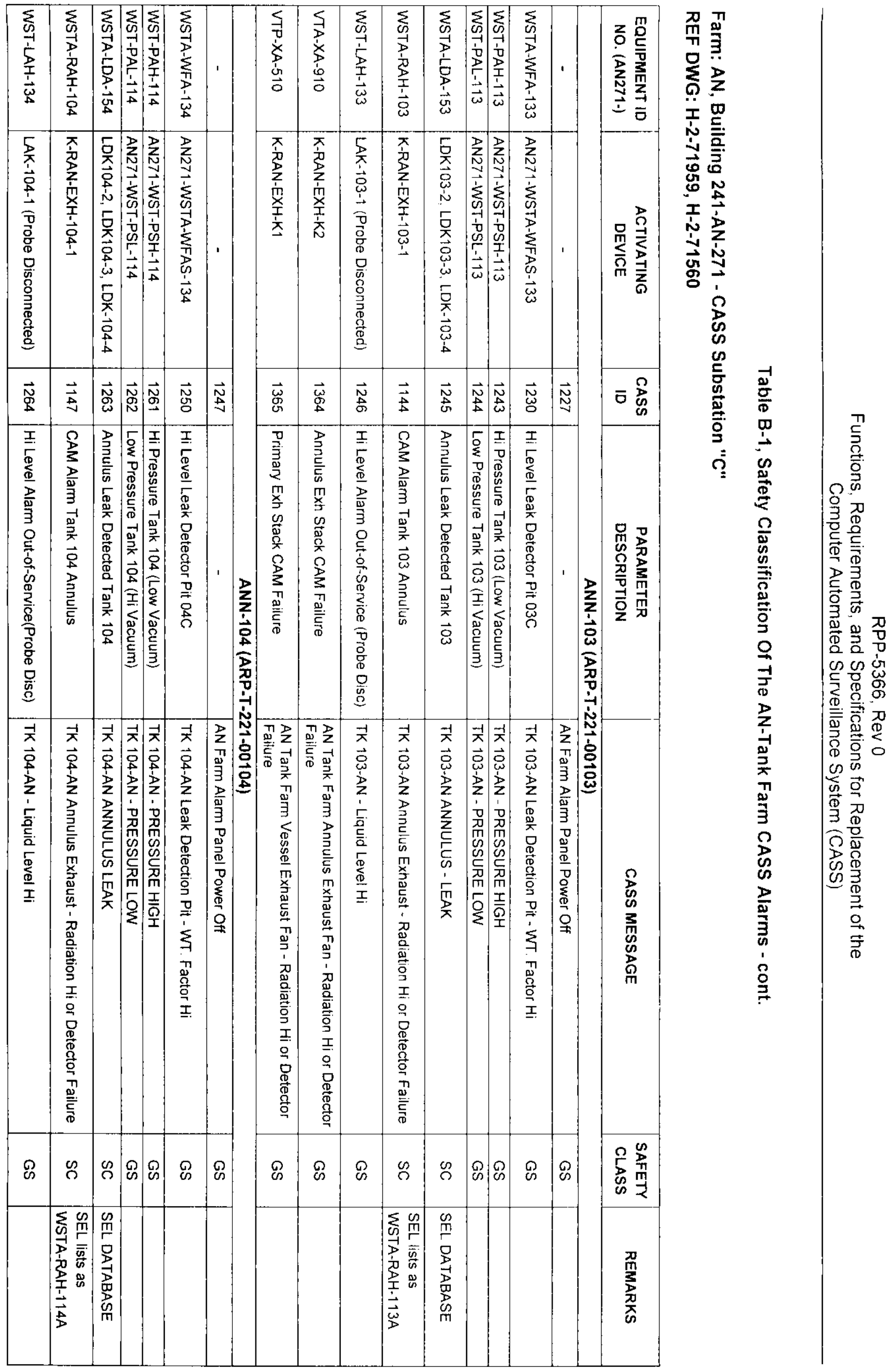




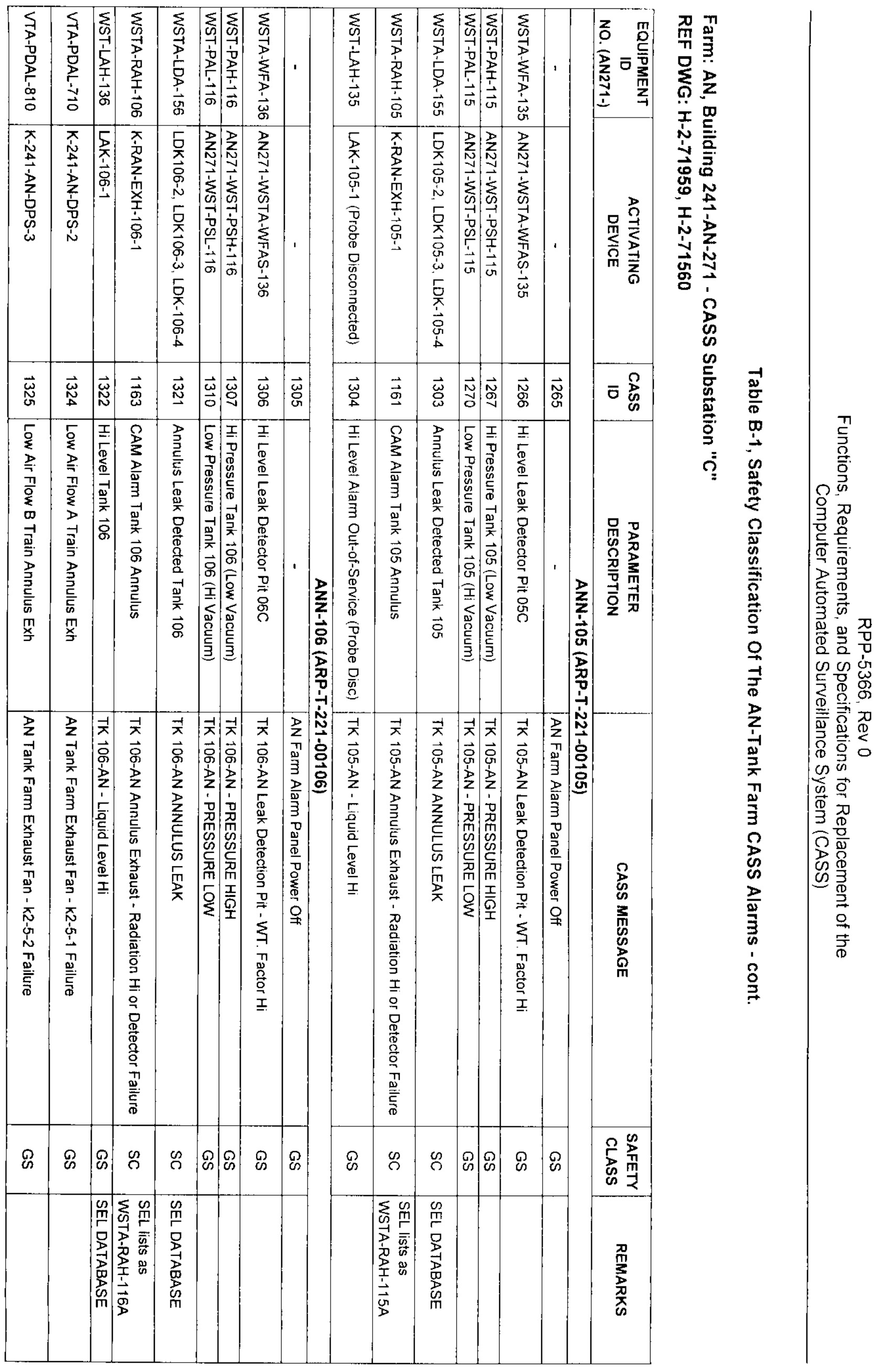




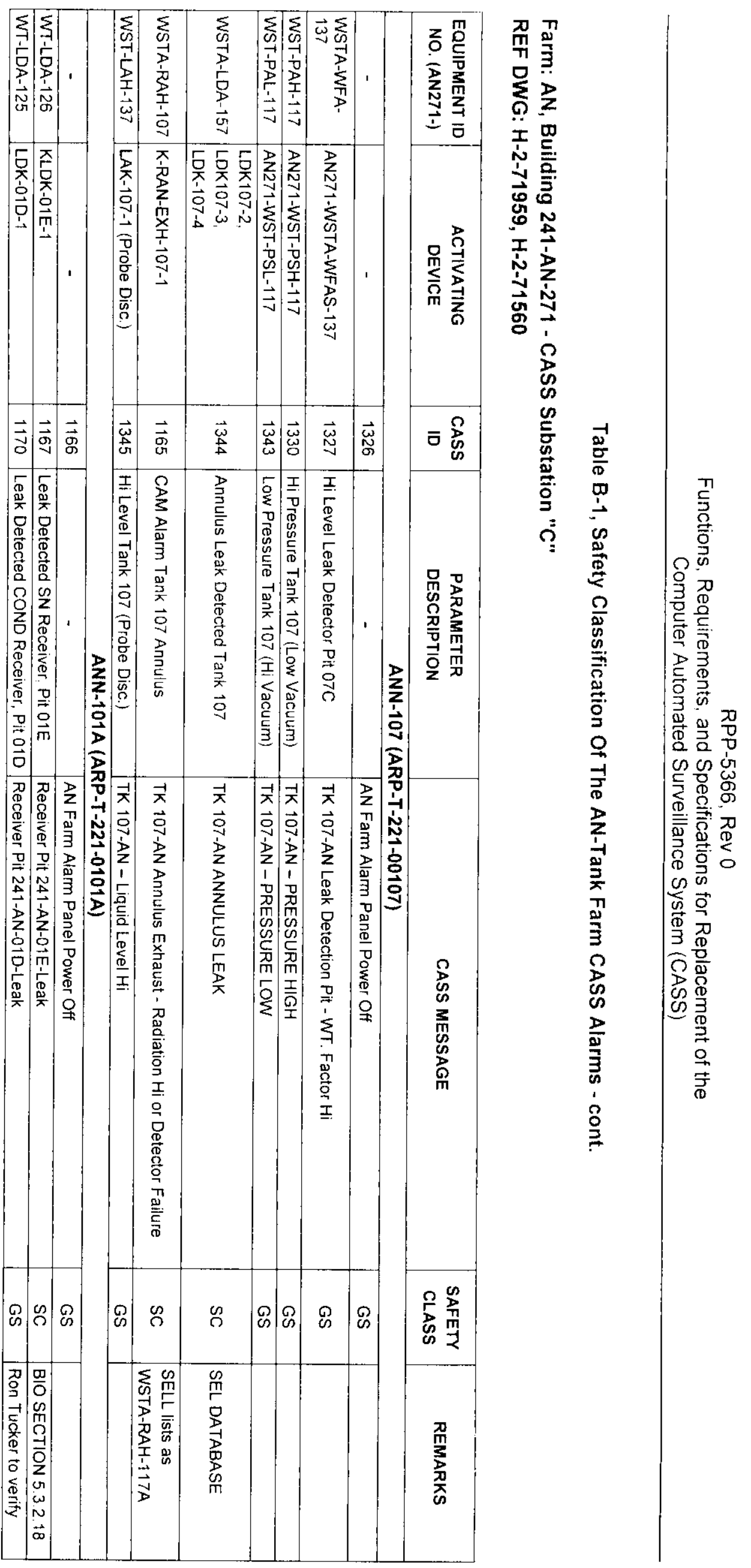




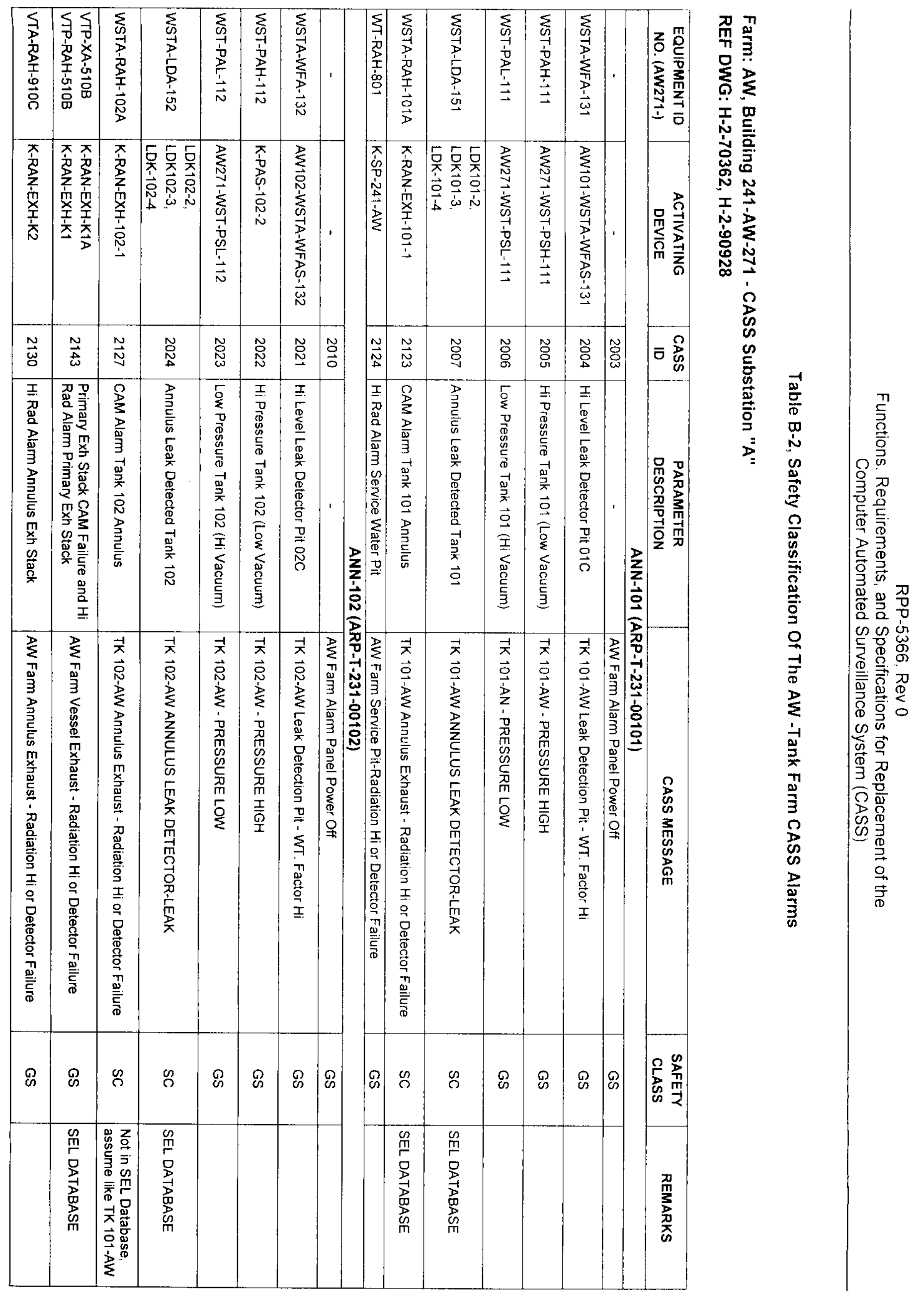




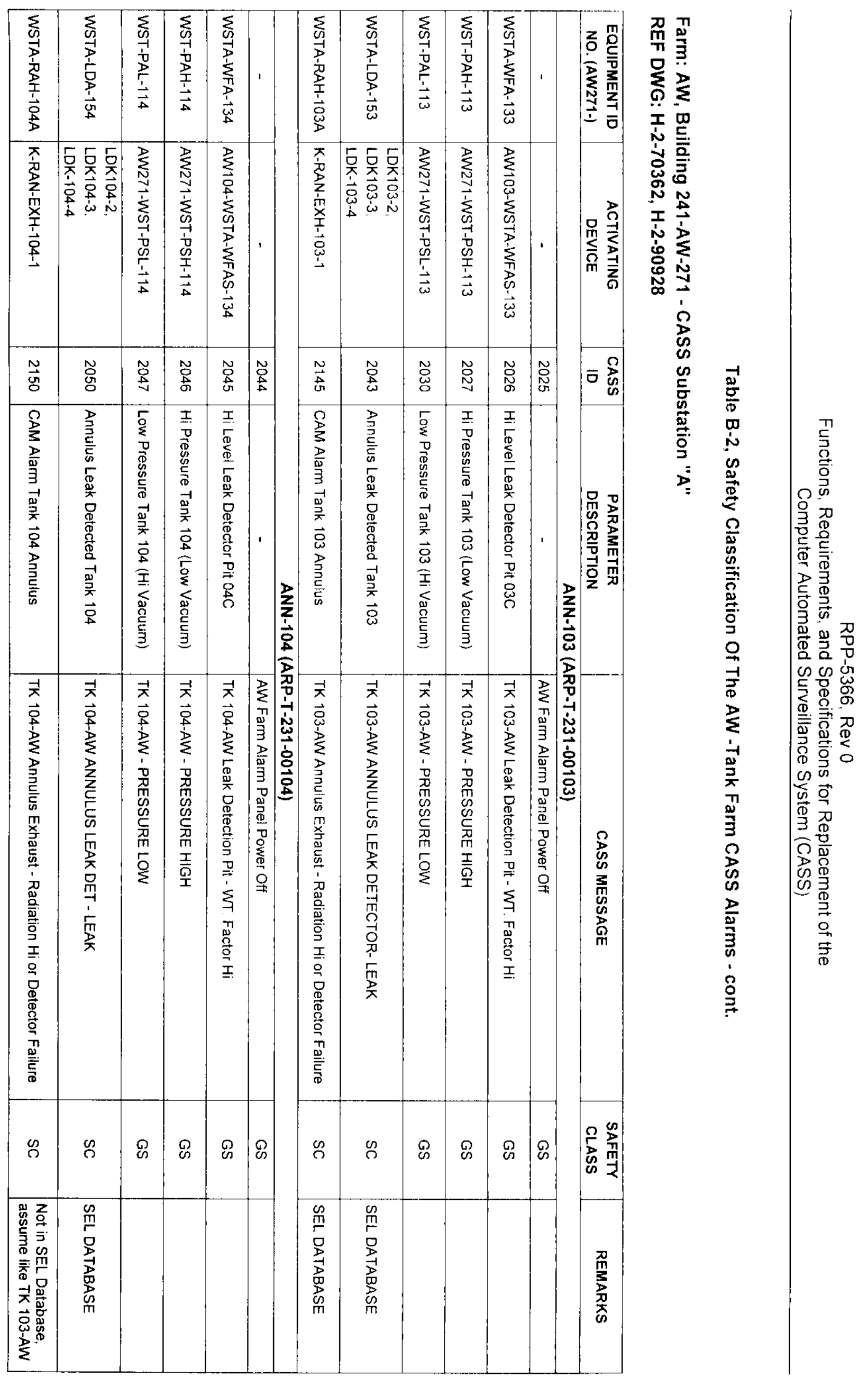




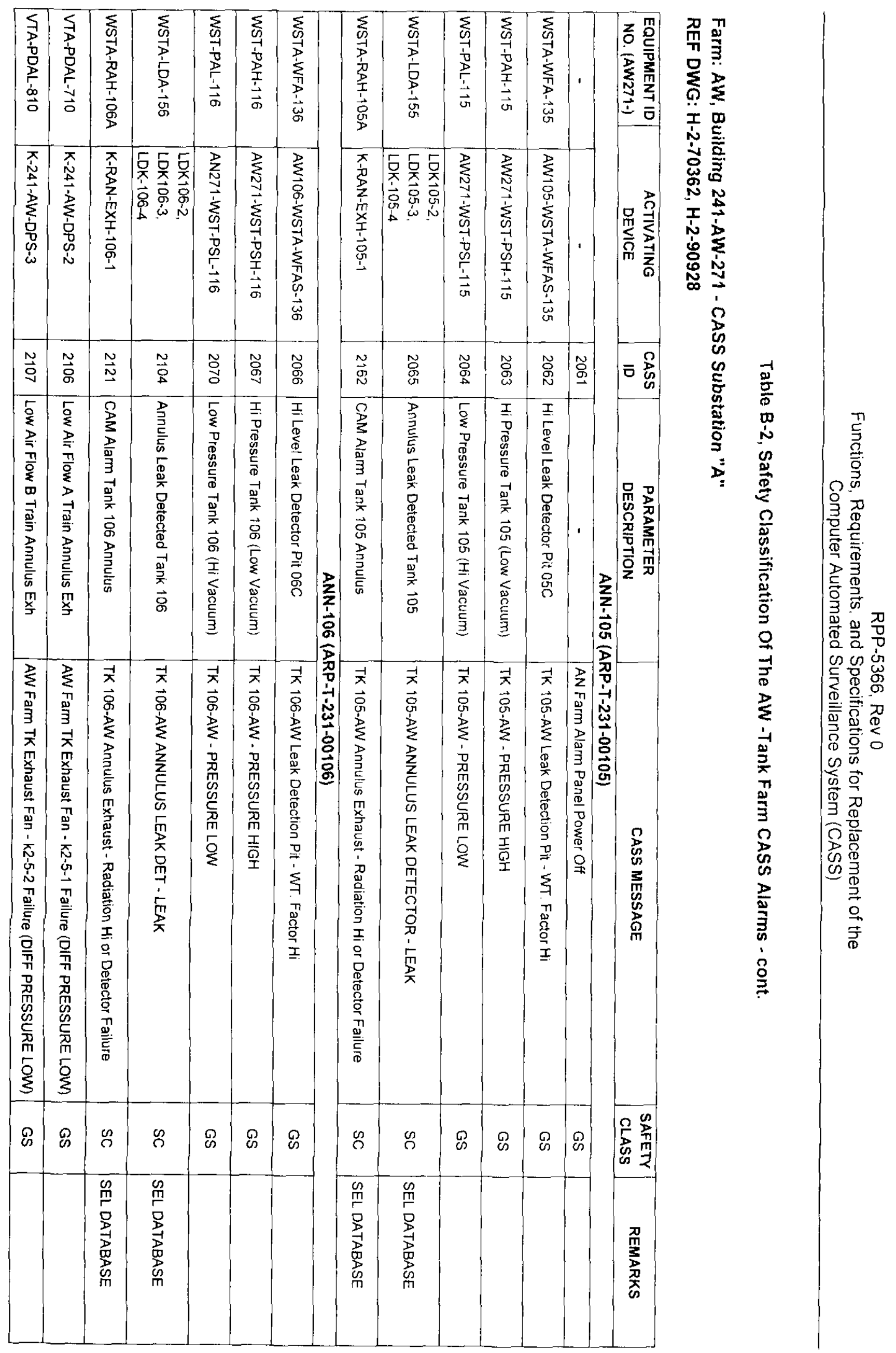




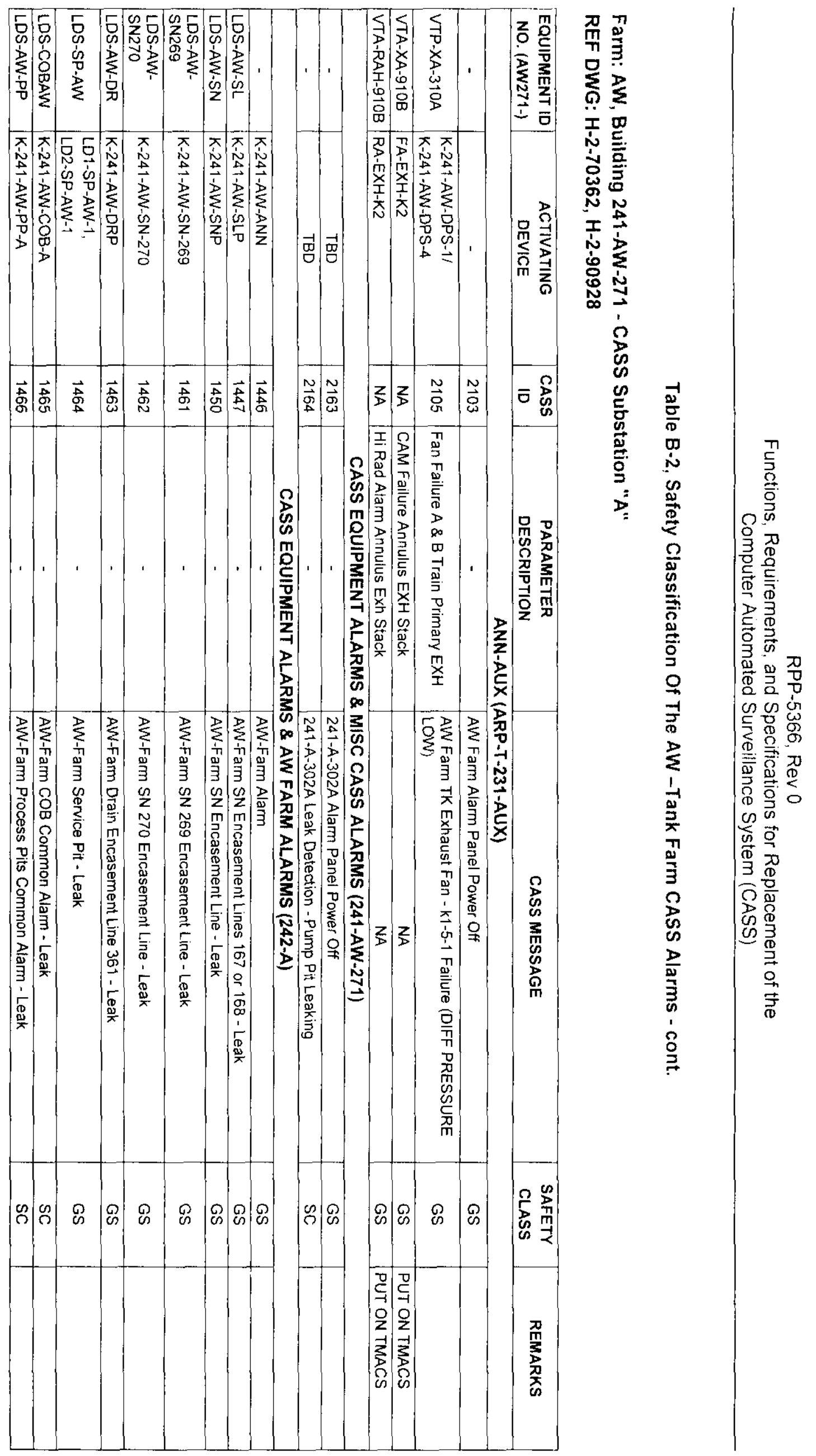




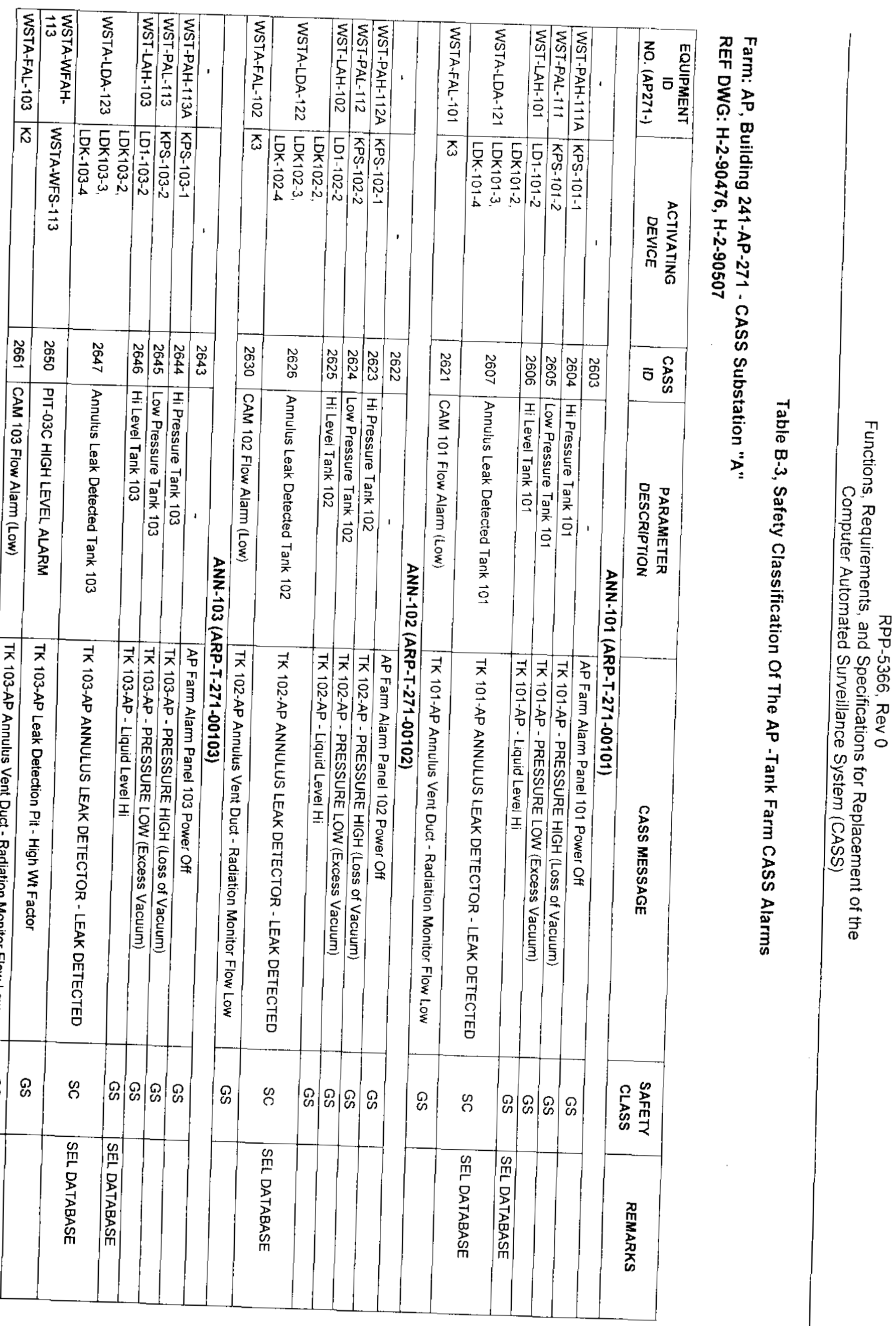




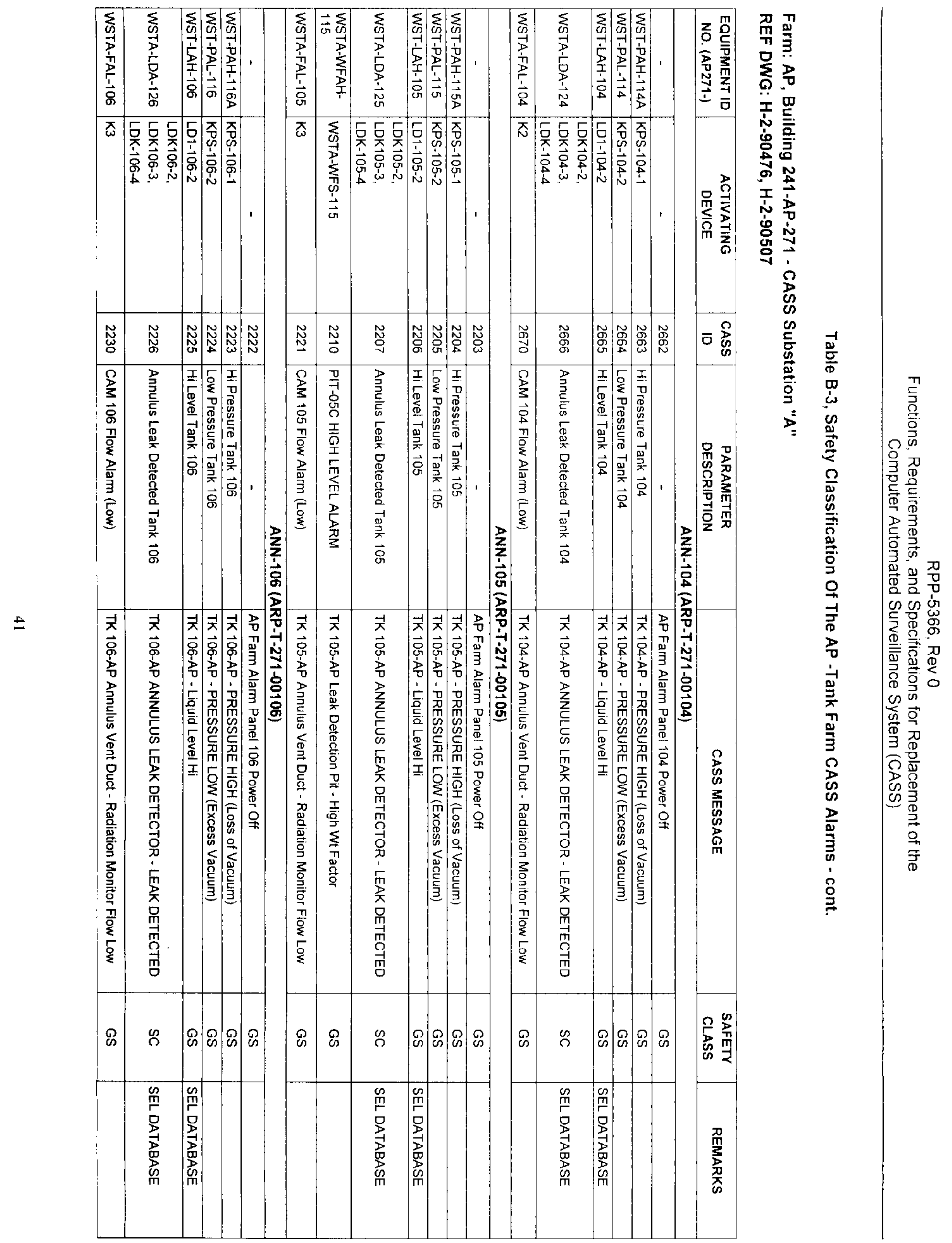




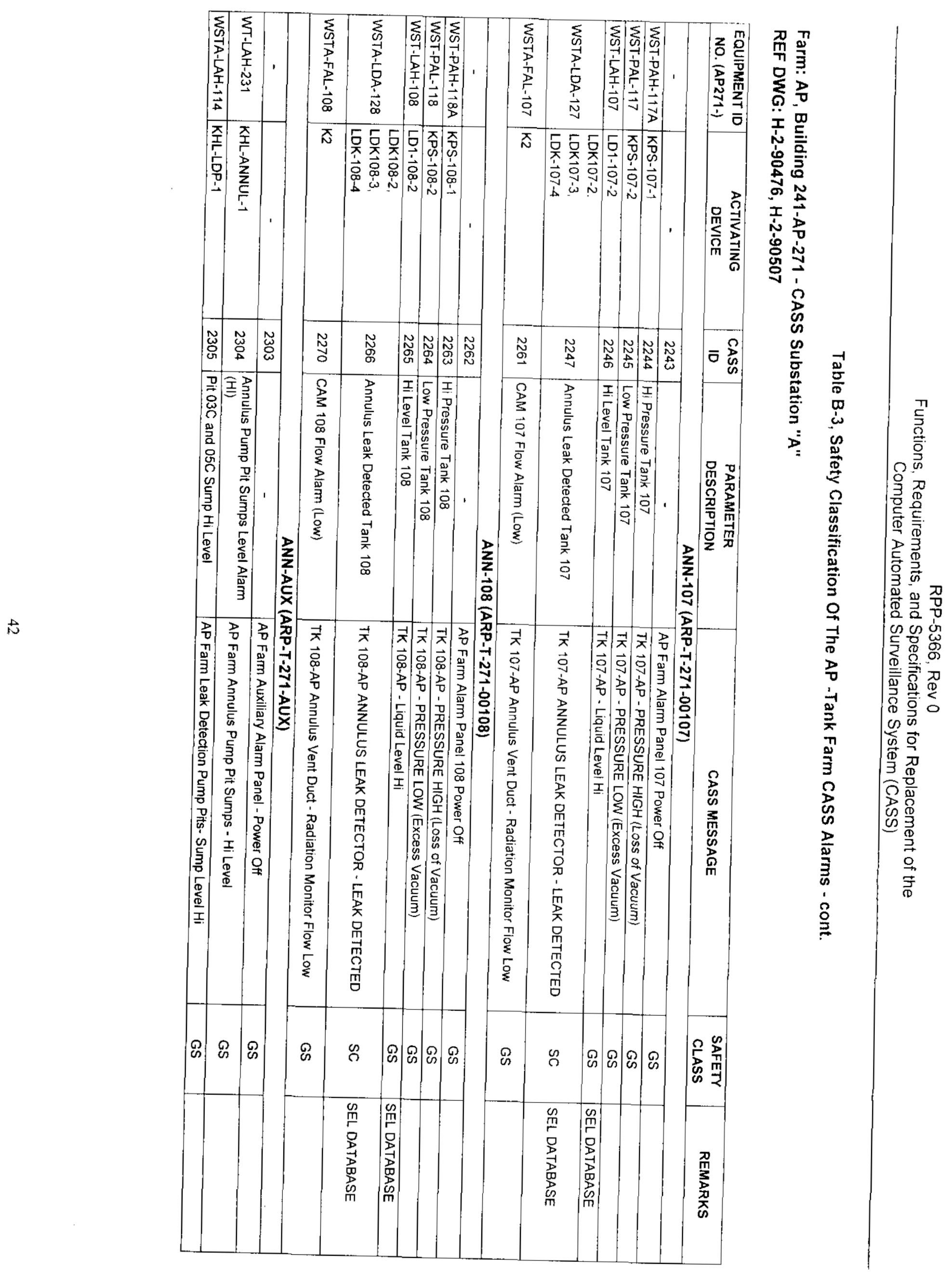




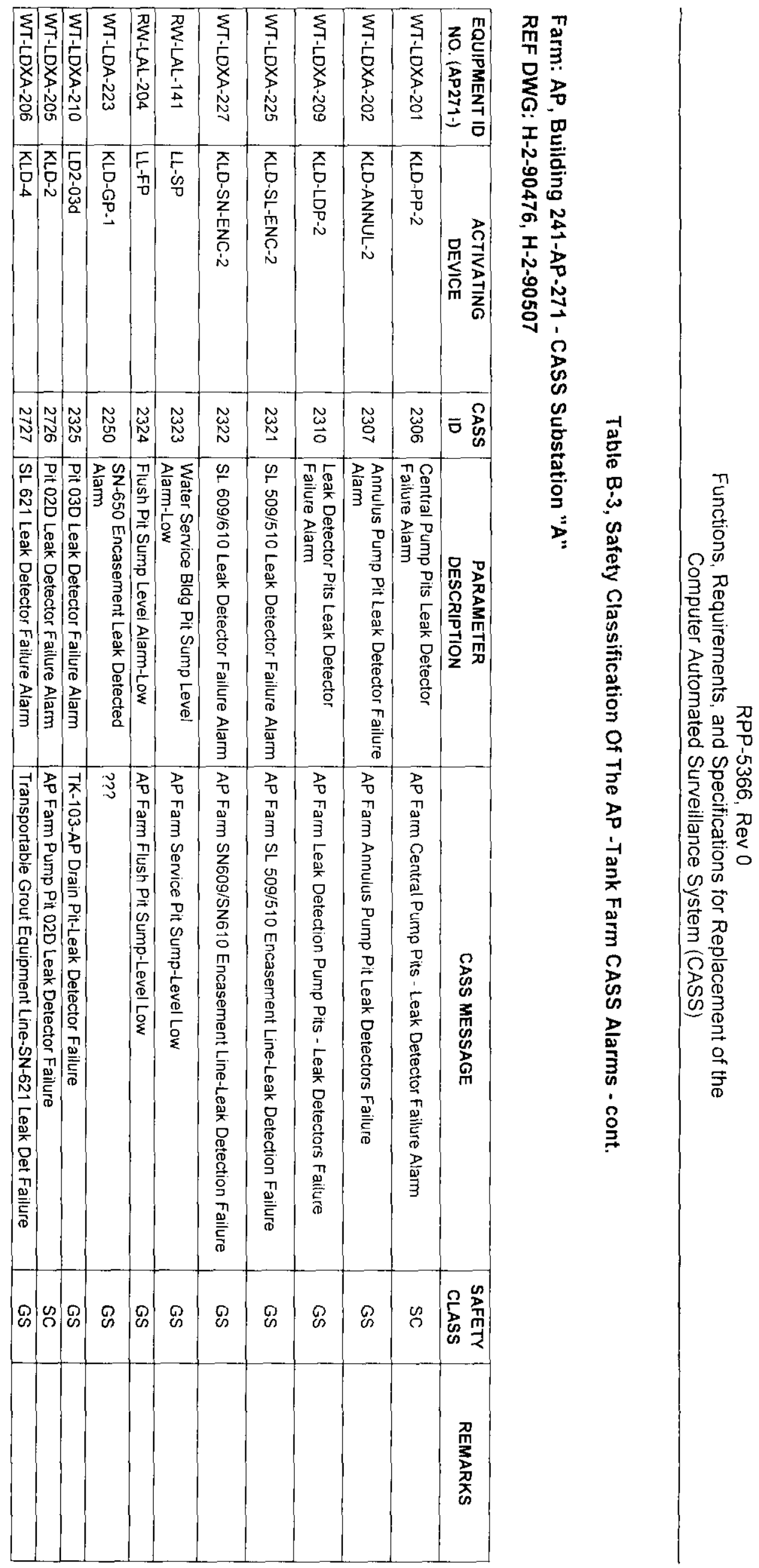




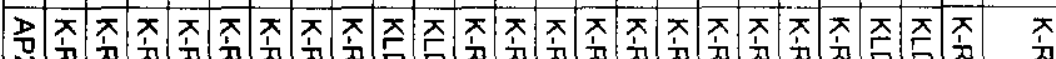

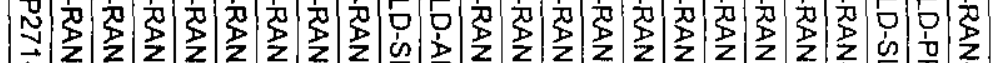

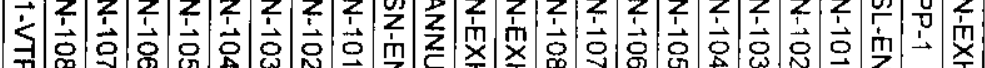

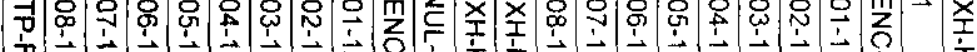

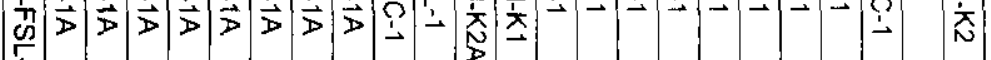
官

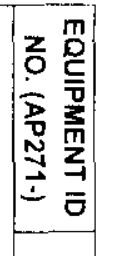

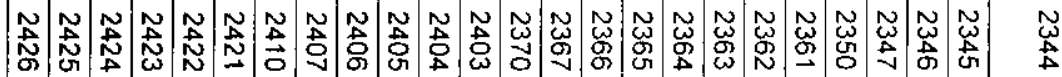

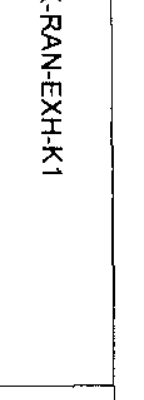

$+$




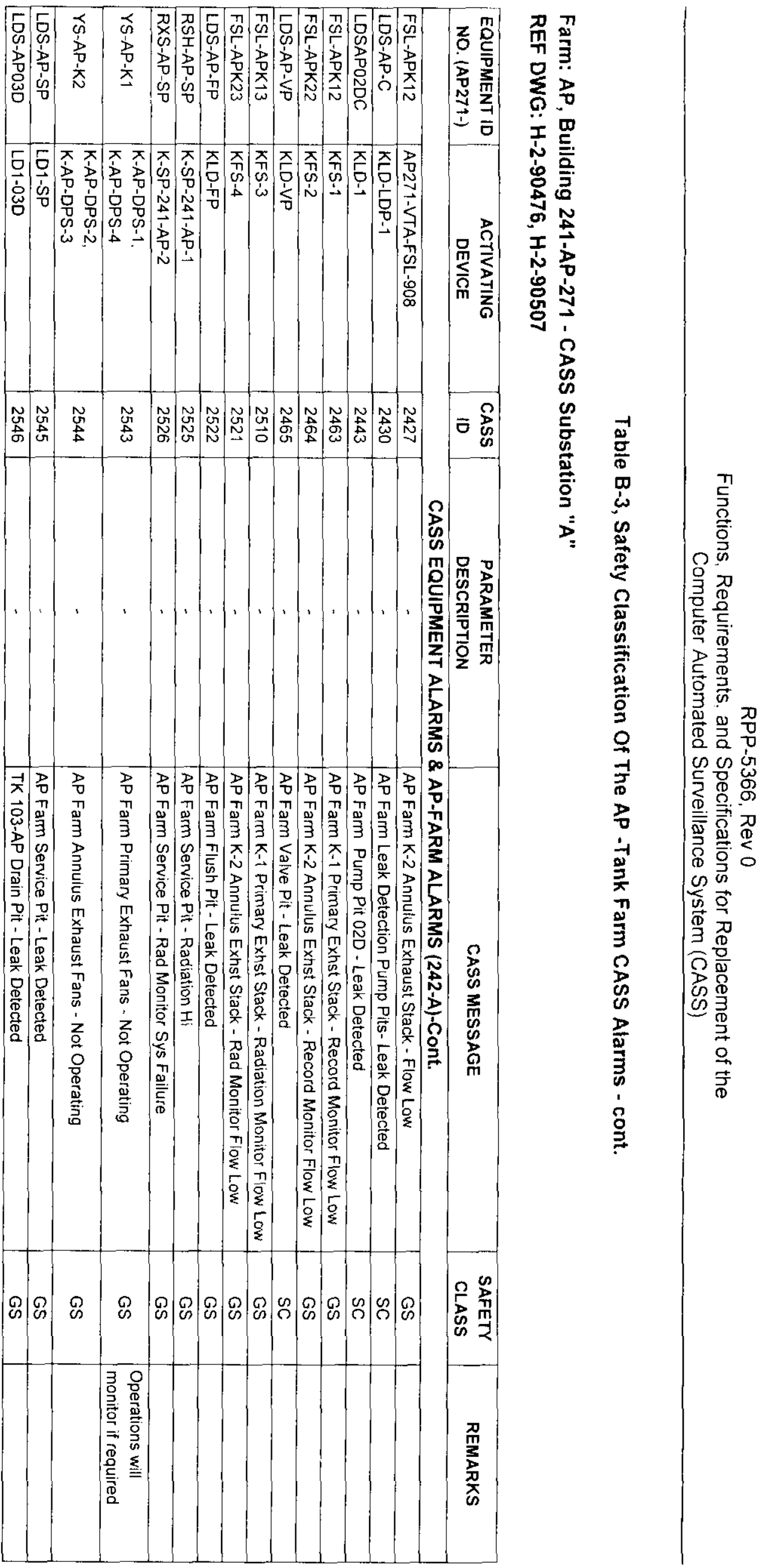




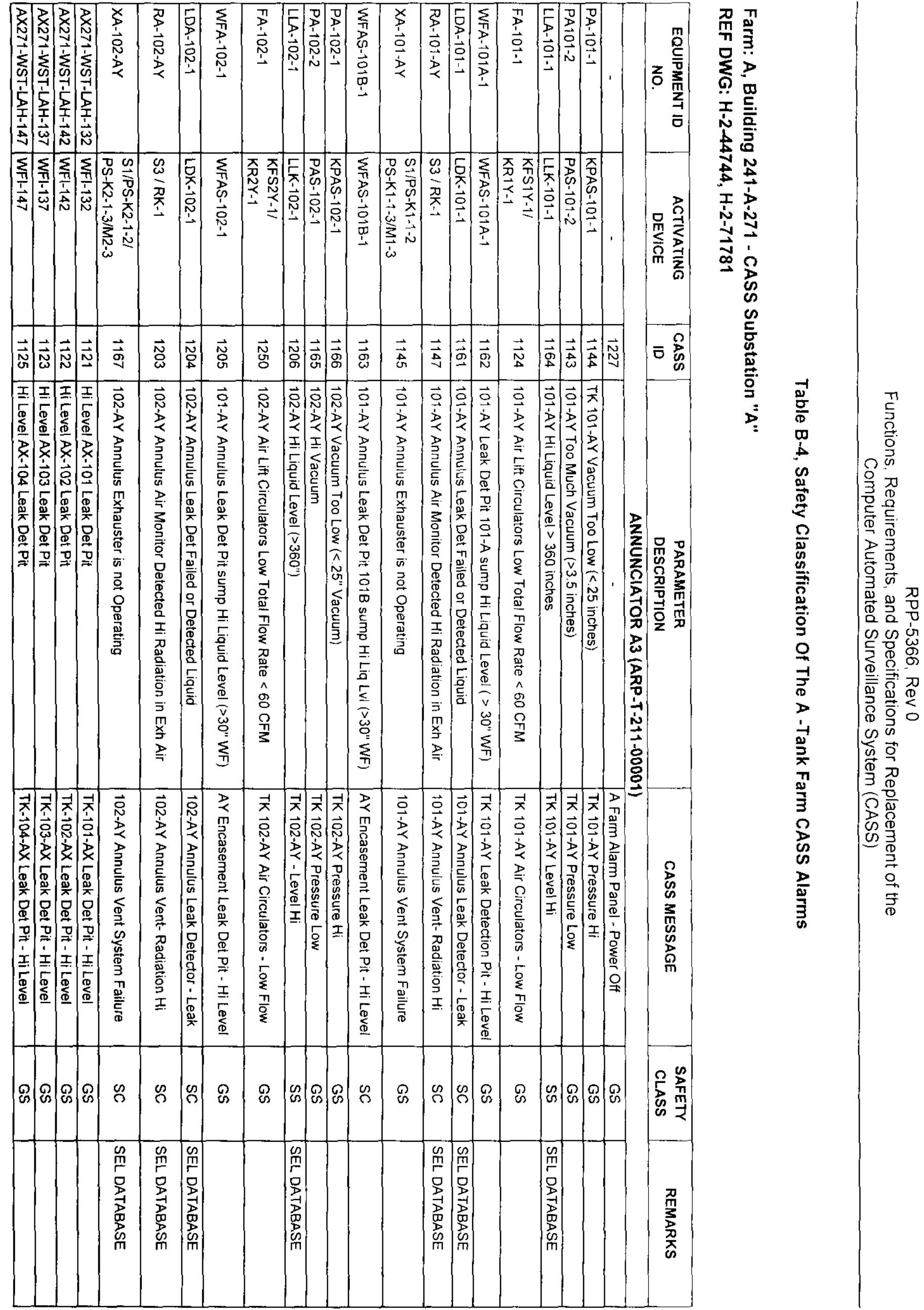




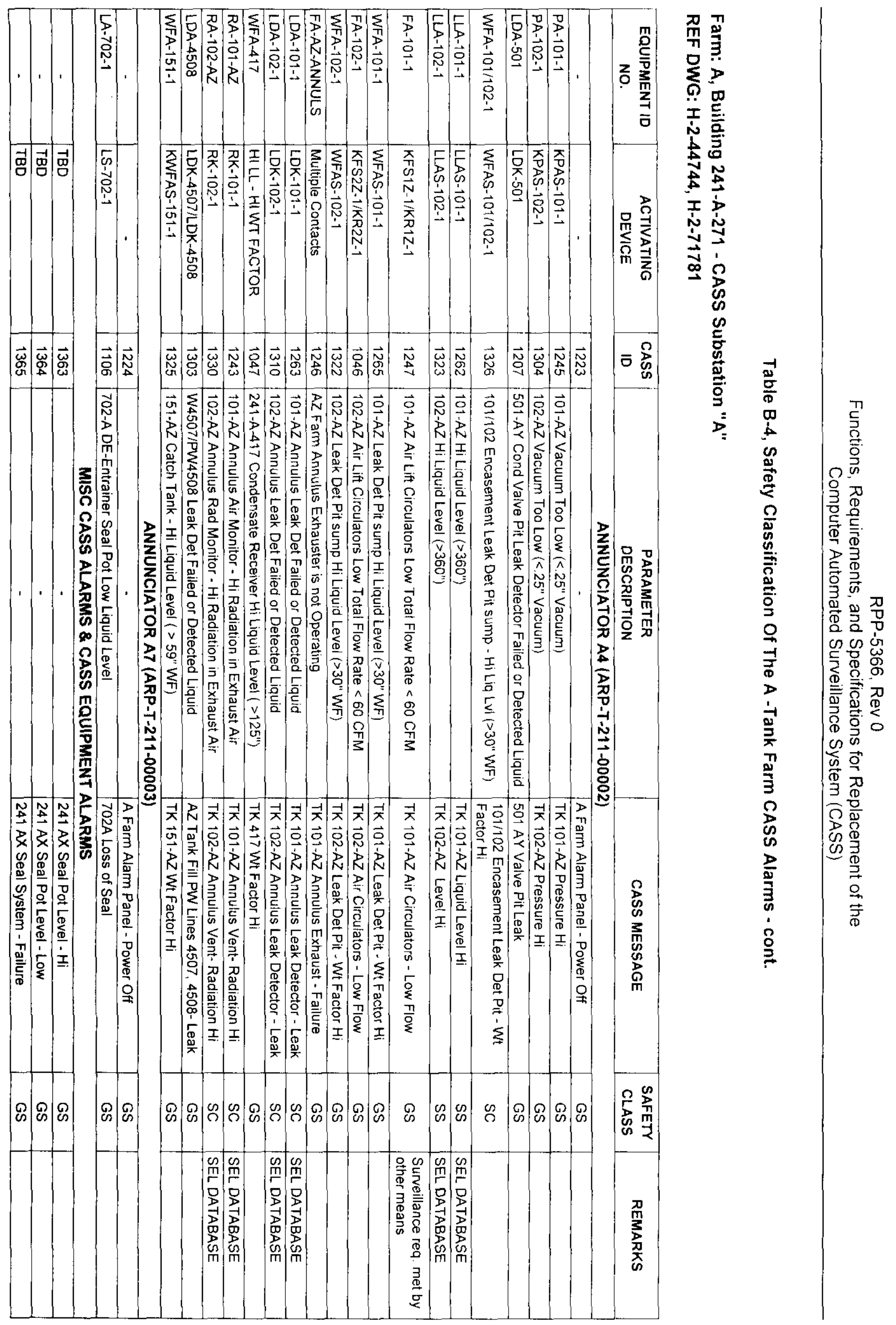




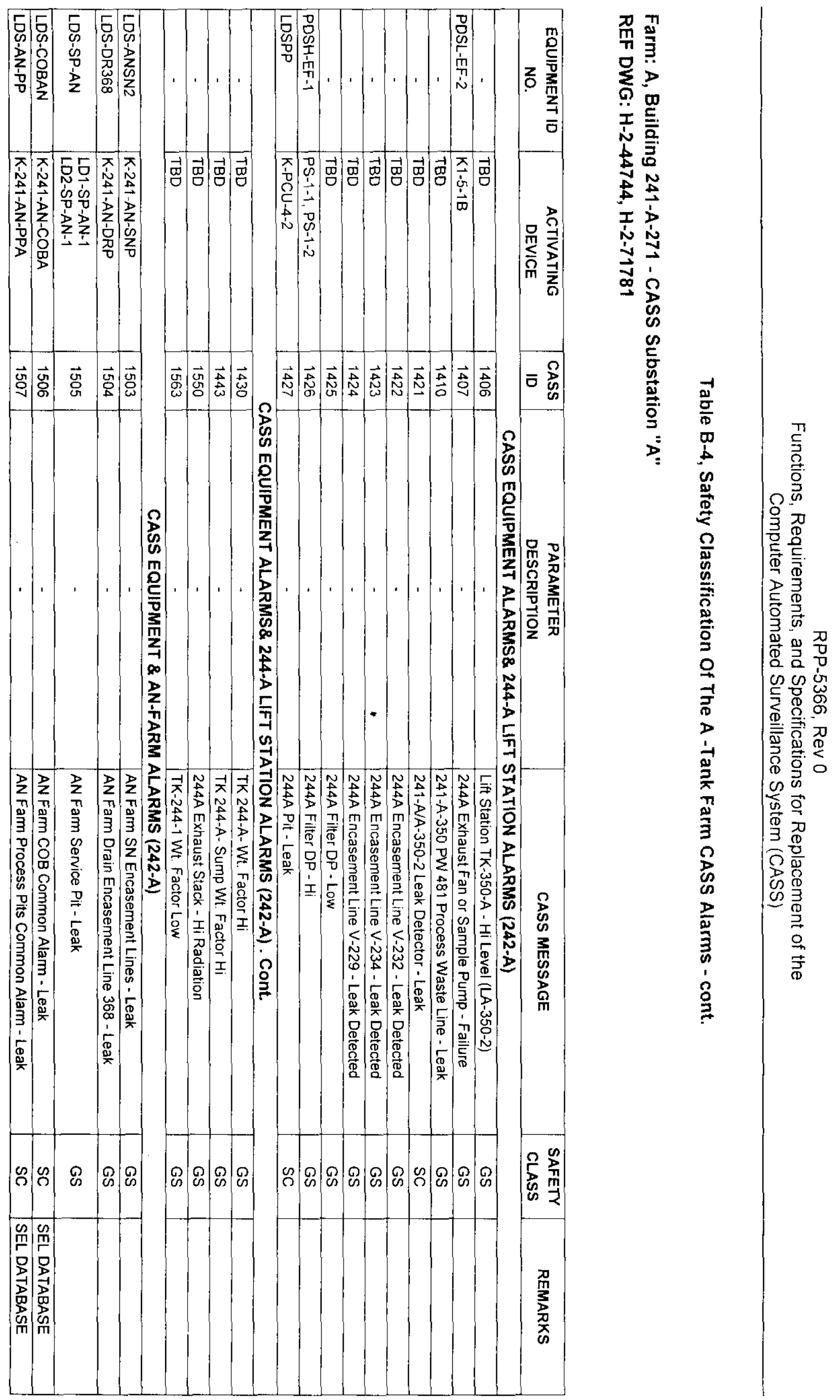




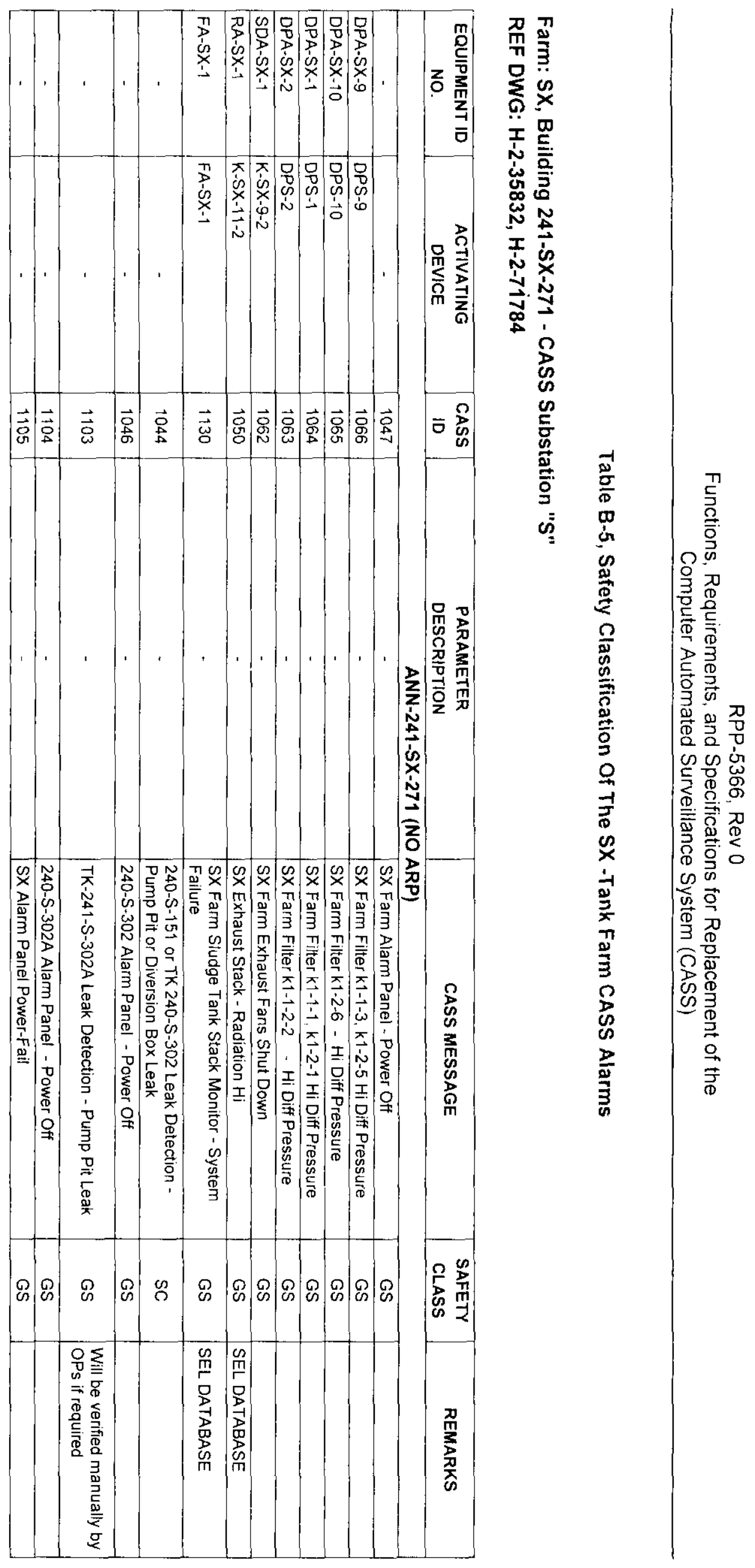




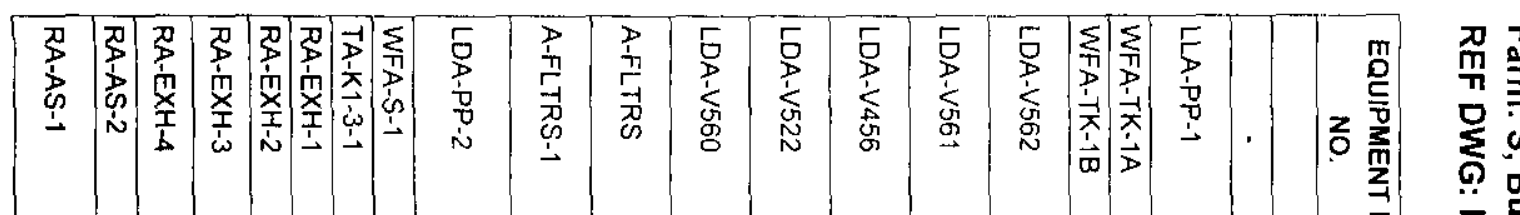

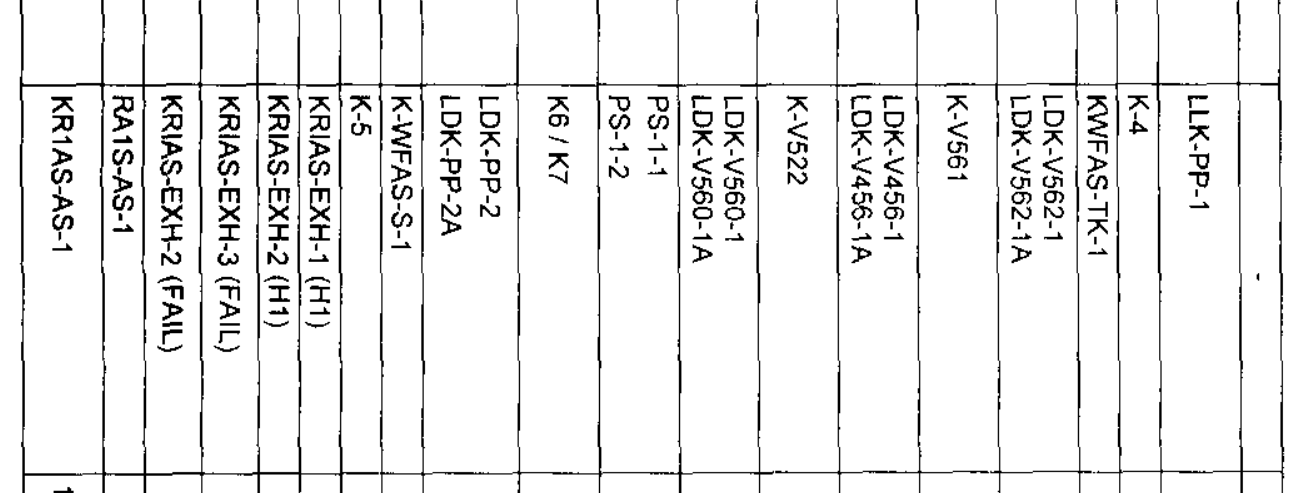

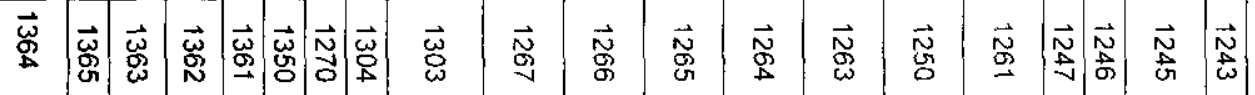

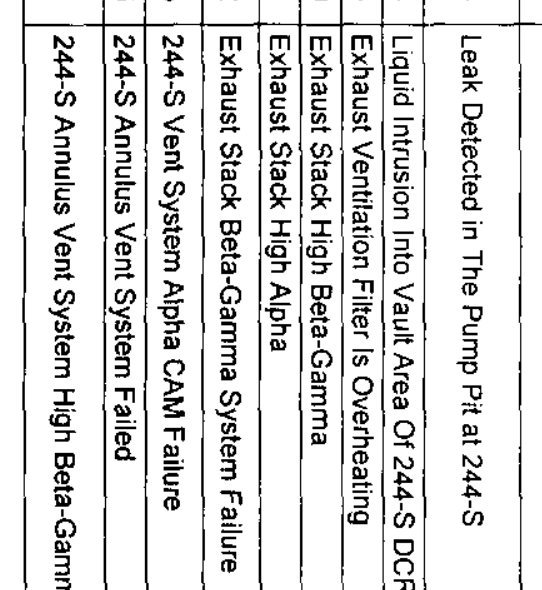

un

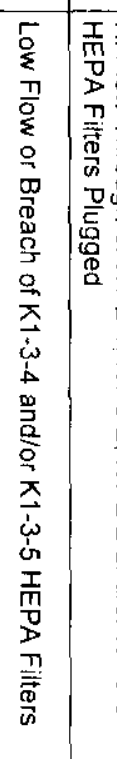

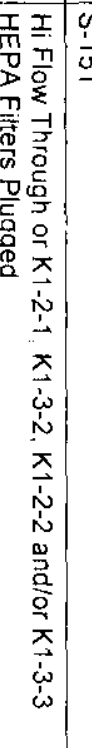

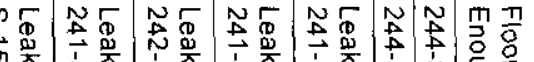

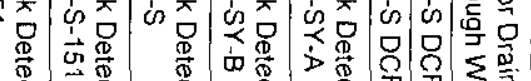

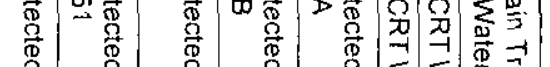

इ 5

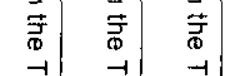

$\overrightarrow{7}$ 골

䆑

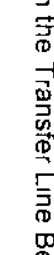

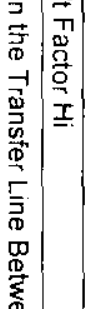

离

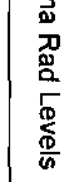

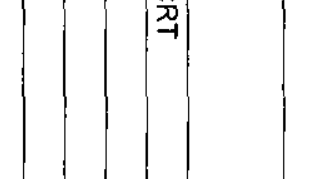

(

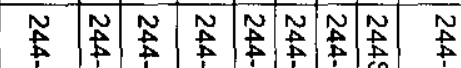

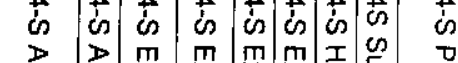

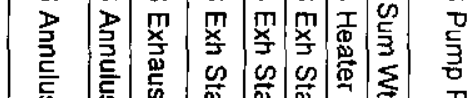

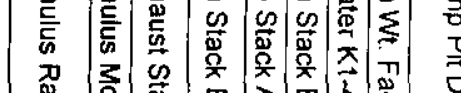

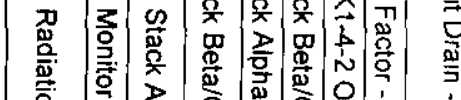

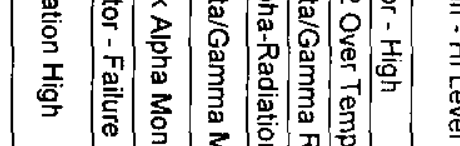

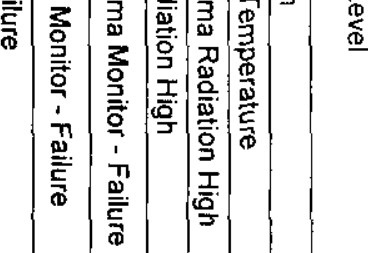

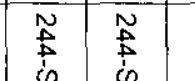

is in is is

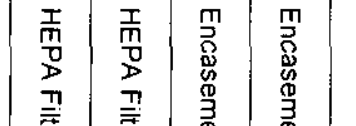

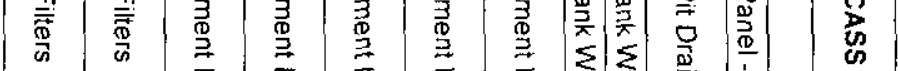

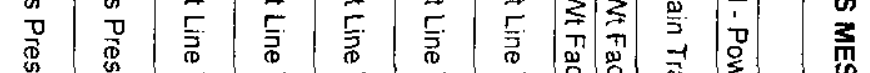

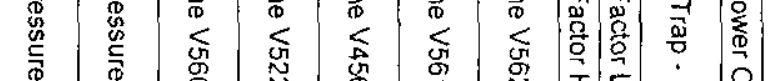

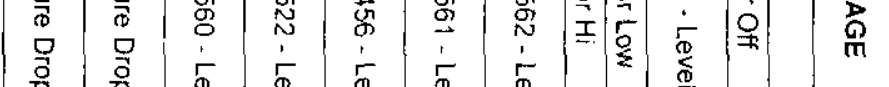

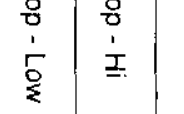

焉

这

$\begin{array}{lll}\mathbb{N} & \mathbb{D} \\ \mathbb{N} & \mathbb{W} \\ & \end{array}$

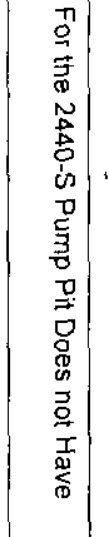

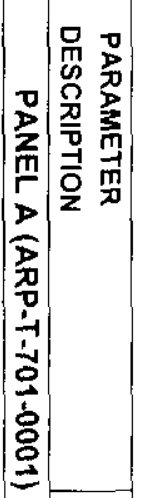

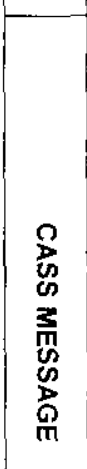

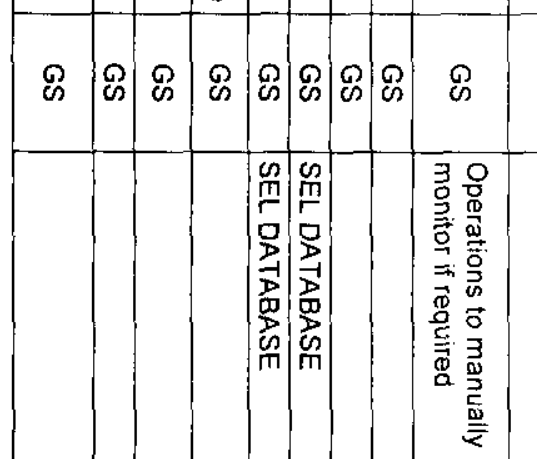




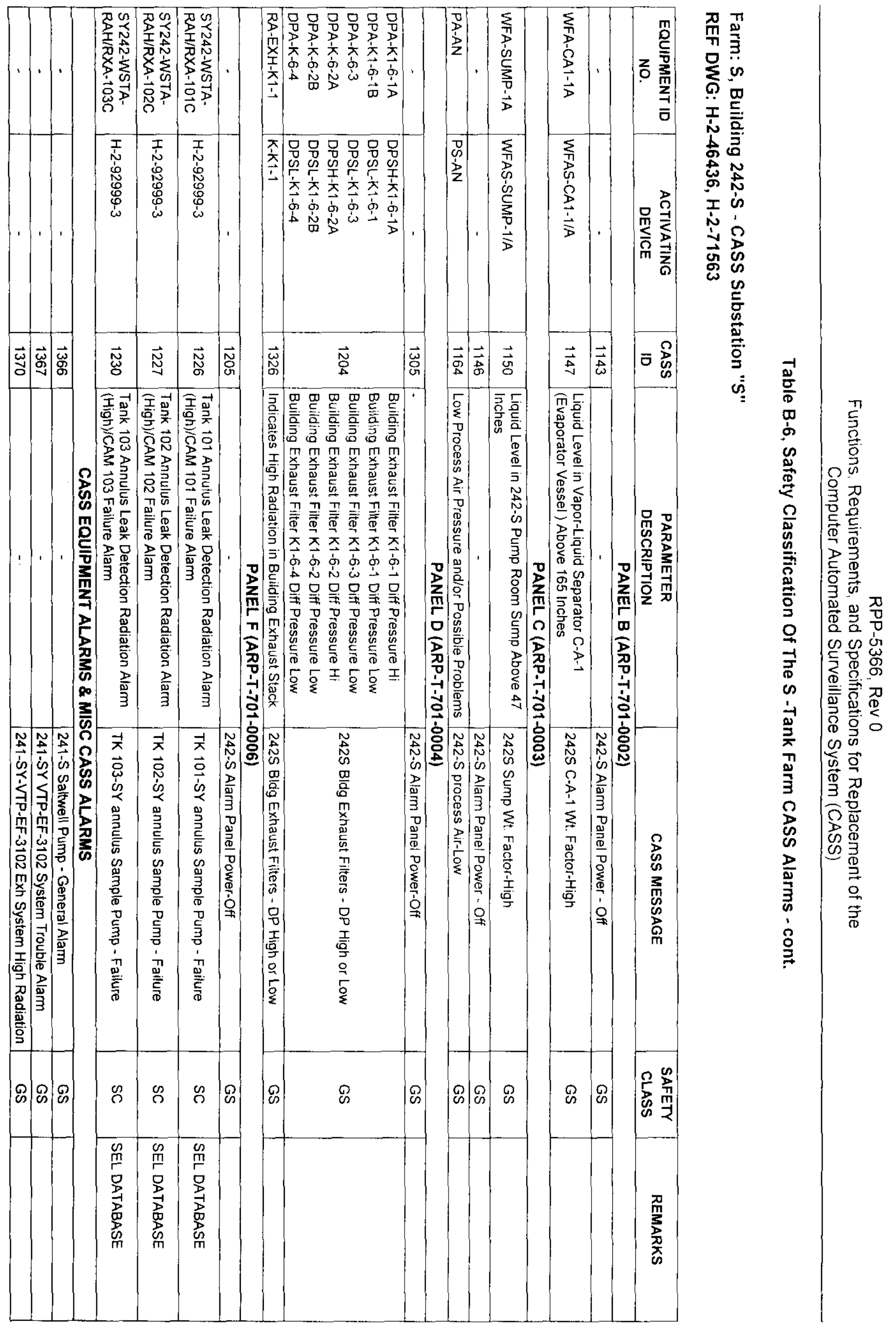




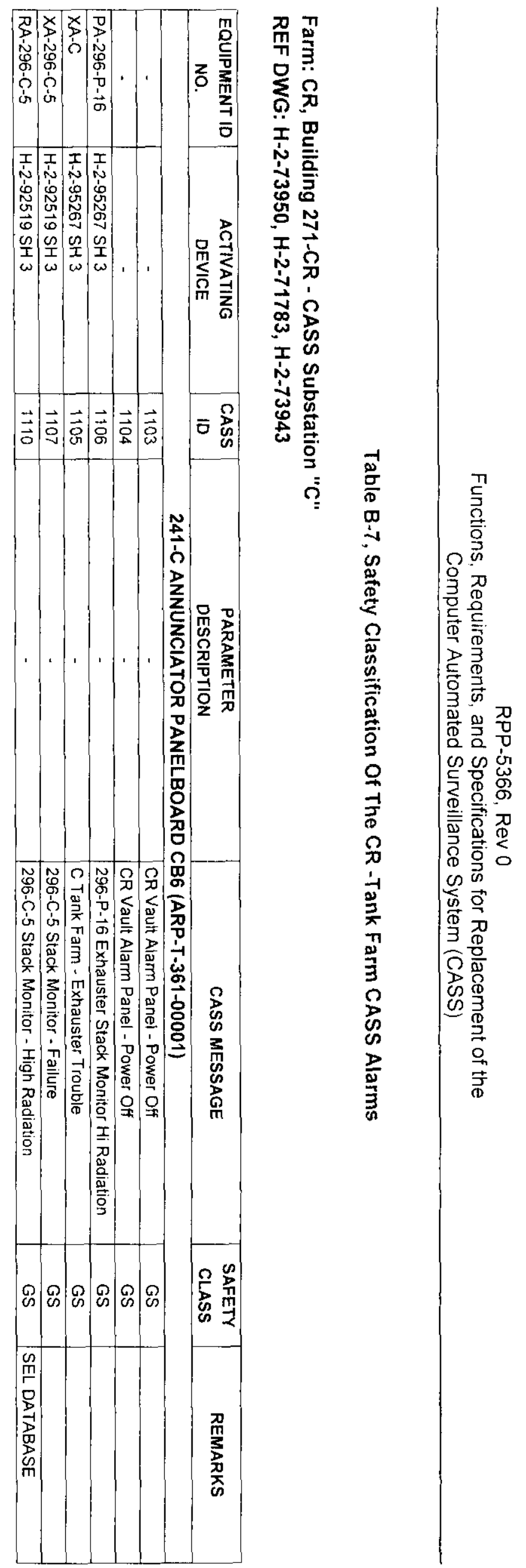




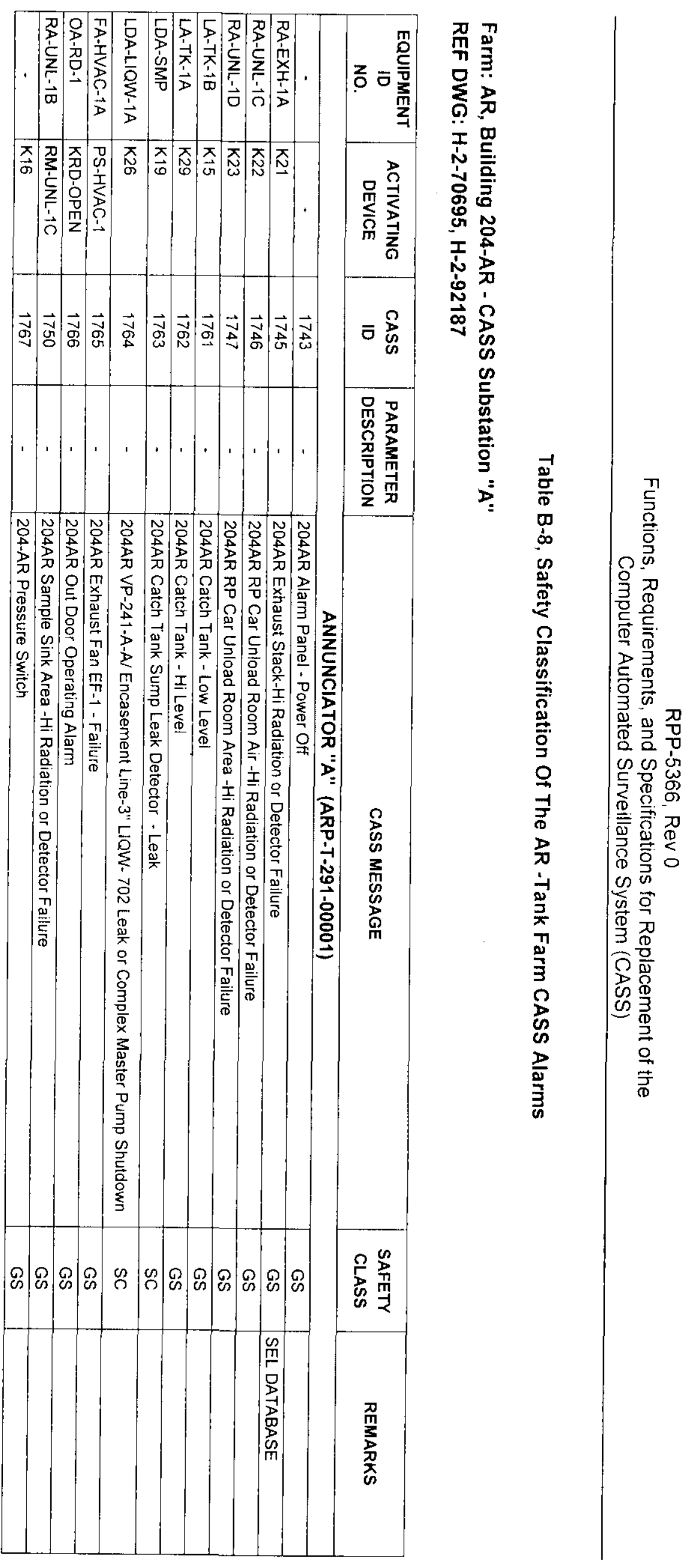




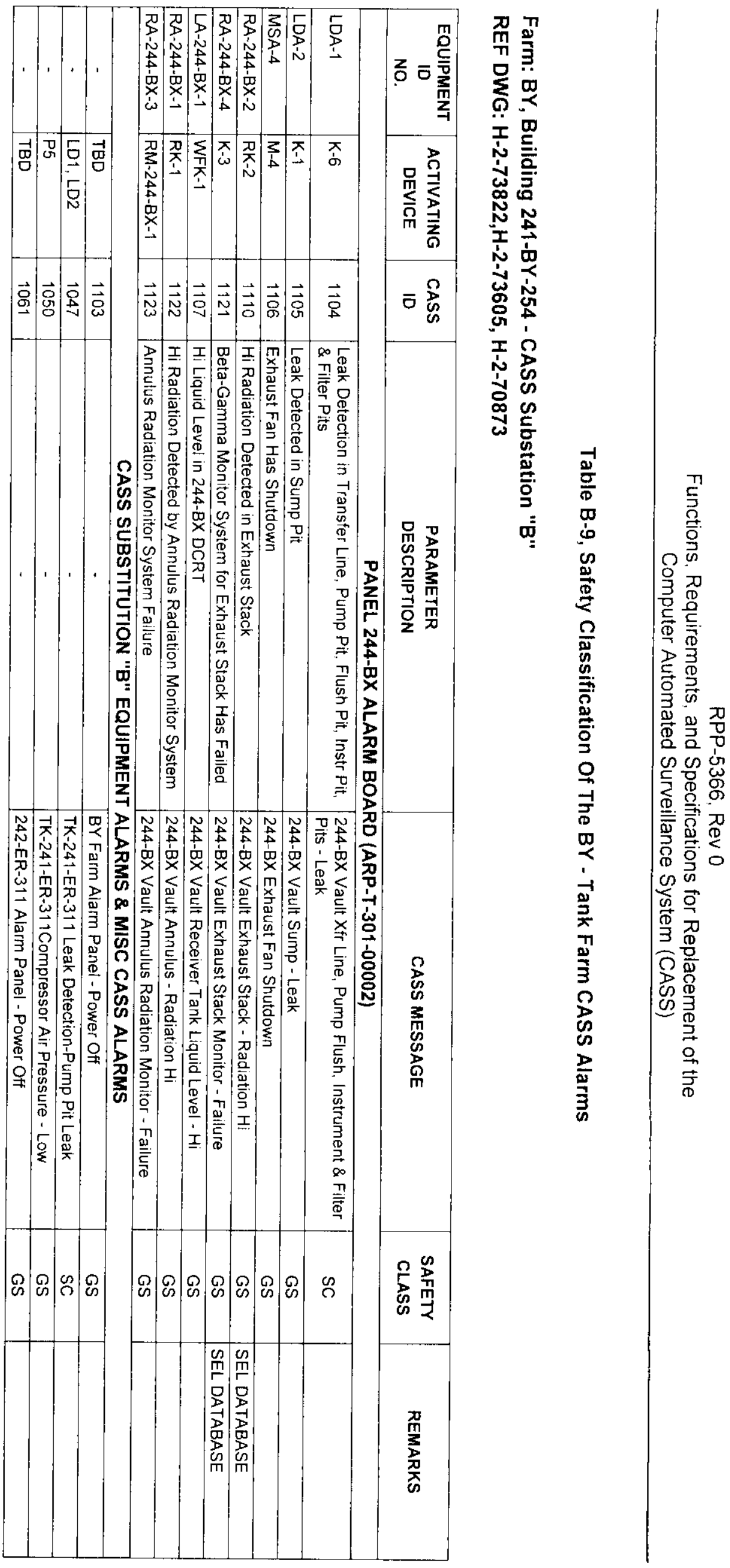




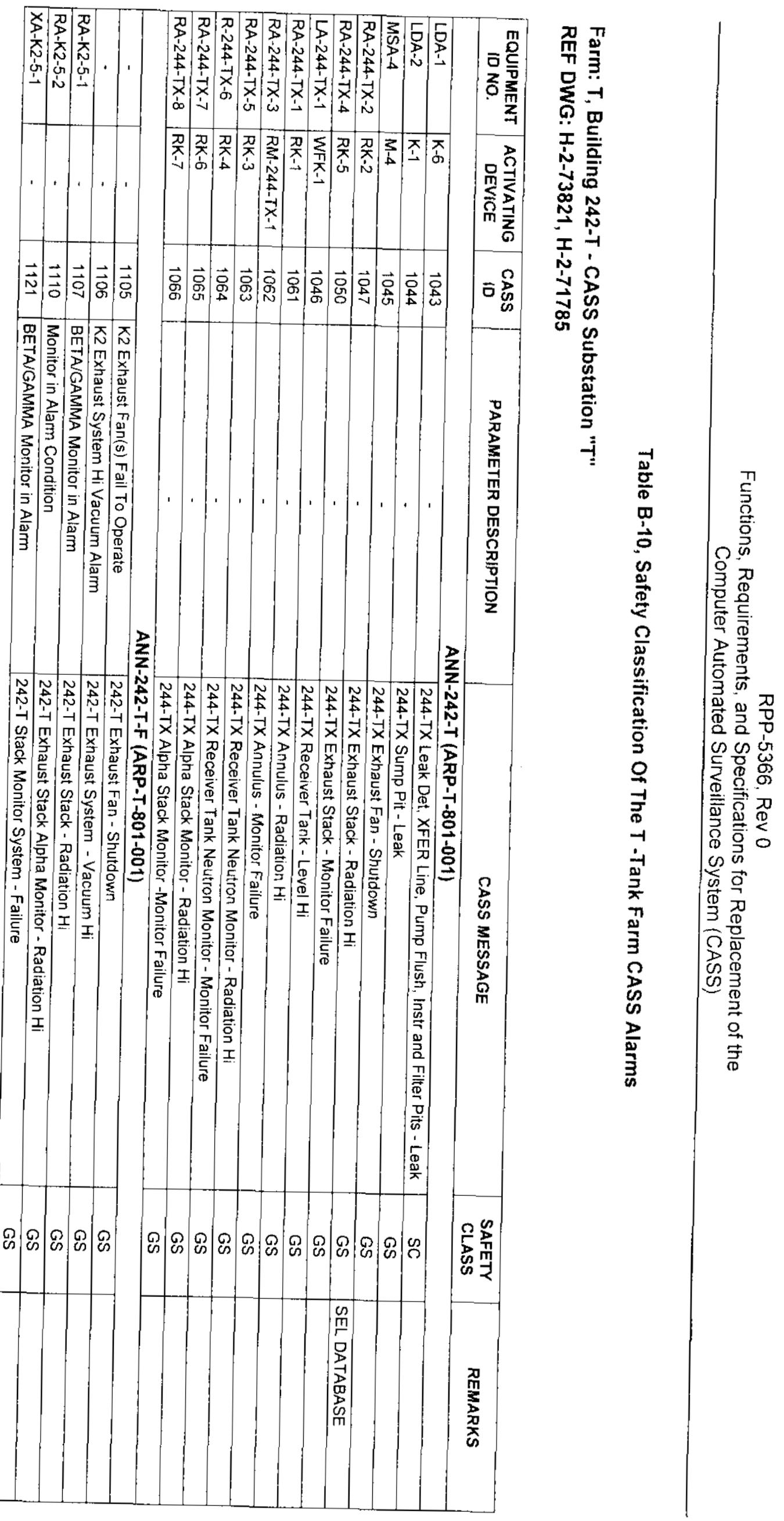




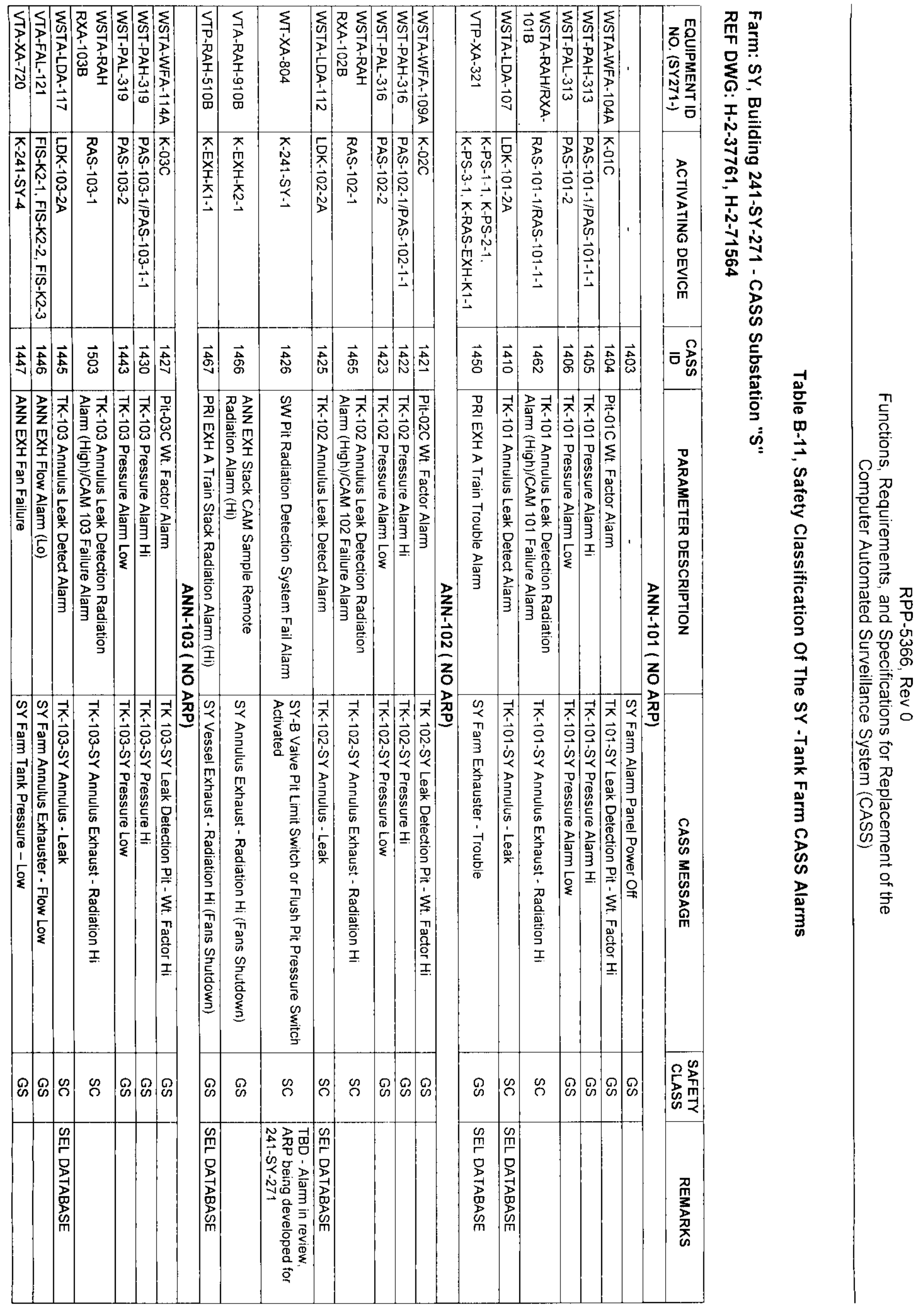

